\title{
Meningeal lymphoid structures are activated under acute and chronic spinal cord pathologies
}

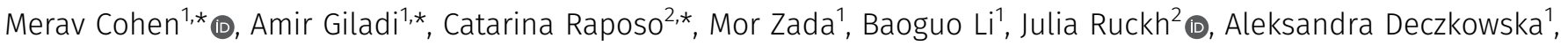 \\ Boaz Mohar ${ }^{2}$ (D), Ravid Shechter ${ }^{2}$, Rachel G Lichtenstein ${ }^{3}$, Ido Amit ${ }^{1}$, Michal Schwartz ${ }^{2,4}$ (D)
}

\begin{abstract}
Tertiary lymphoid structures (TLS) are organized aggregates of B and $T$ cells formed ectopically during different stages of life in response to inflammation, infection, or cancer. Here, we describe formation of structures reminiscent of TLS in the spinal cord meninges under several central nervous system (CNS) pathologies. After acute spinal cord injury, B and T lymphocytes locally aggregate within the meninges to form TLS-like structures, and continue to accumulate during the late phase of the response to the injury, with a negative impact on subsequent pathological conditions, such as experimental autoimmune encephalomyelitis. Using a chronic model of spinal cord pathology, the mSOD1 mouse model of amyotrophic lateral sclerosis, we further showed by single-cell RNA-sequencing that a meningeal lymphocyte niche forms, with a unique organization and activation state, including accumulation of pre-B cells in the spinal cord meninges. Such a response was not found in the CNS-draining cervical lymph nodes. The present findings suggest that a special immune response develops in the meninges during various neurological pathologies in the CNS, a possible reflection of its immune privileged nature.
\end{abstract}

DOI 10.26508/lsa.202000907 | Received 15 September 2020 | Revised 27 October 2020 | Accepted 28 October 2020 | Published online 4 December 2020

\section{Introduction}

Following any deviation from homeostasis in the central nervous system (CNS), the immune response is activated to facilitate repair and to resolve the detrimental parenchymal inflammation. Despite the privileged nature of the CNS, many immunological process take place within its boundaries, both in homeostasis and under pathological conditions, with similarities to those that occur in the periphery (Lalancette-Hebert et al, 2007; Liesz et al, 2009; Shechter et al, 2009; David \& Kroner, 2011; London et al, 2011, 2013; Martino et al, 2011;
Michaud et al, 2013; Cohen et al, 2014, 2017; Peruzzotti-Jametti et al, 2014; Raposo et al, 2014; Kunis et al, 2015; Russo \& McGavern, 2015).

Tertiary lymphoid structures (TLS) are ectopic lymphoid aggregates formed locally in non-lymphoid tissues after organ development, induced by pathologies characterized by ongoing chronic inflammation, infection, autoimmunity and cancer (Kendall et al, 2007; GeurtsvanKessel et al, 2009; de Chaisemartin et al, 2011; DieuNosjean et al, 2014). TLS share cellular and organizational features with secondary lymphoid organs (SLOs), including segregation of B- and T-cell areas that are supported by stromal/vascular components, and presence of activated germinal centers (GCS) with follicular DCs, where clonal expansion, somatic mutation, and isotype switching can occur (Gommerman \& Browning, 2003). Their formation has been proposed to involve defective lymphatic drainage and continuous local antigen stimulation (Thaunat et al, 2006).

Recent studies in the field of CNS lymphatic drainage revealed that in homeostasis, a lymphatic vasculature is present in the dural sinuses of the brain meninges (Weller et al, 2009; Aspelund et al, 2015; Louveau et al, 2015), in addition to the perivascular pathways that drain interstitial fluid from the brain parenchyma, and cerebrospinal fluid (CSF) from the subarachnoid space to cervical lymph nodes (cLNs) (Carare et al, 2014; Lochhead et al, 2015). These observations, together with our findings that entry of immuno-regulatory cells to sites of injured CNS parenchyma is orchestrated through the brain's border, the choroid plexus (CP) epithelium (Kunis et al, 2013; Shechter et al, 2013; Raposo et al, 2014), suggest that the meningeal lymphatic niche might become activated and participate in the immunological network triggered by CNS injury. TLS are widespread across different tissues and under different pathological conditions in the periphery. Within the CNS, their formation in the form of B-cell aggregates that execute a GC response was mainly identified in brain meninges under inflammatory diseases of the brain, such as multiple sclerosis, and its mouse model, experimental autoimmune encephalomyelitis (EAE) (Columba-Cabezas et al, 2006; Howell et al, 2011; Peters et al, 2011; Kuerten et al, 2012; Pikor et al, 2015; Lehmann-Horn et al, 2016; Bevan et al, 2018; Magliozzi et al, 2019).

${ }^{1}$ Department of Immunology, Weizmann Institute of Science, Rehovot, Israel ${ }^{2}$ Department of Neurobiology, Weizmann Institute of Science, Rehovot, Israel ${ }^{3}$ Avram and Stella Goldstein-Goren Department of Biotechnology Engineering, Ben-Gurion University of the Negev, Beersheba, Israel ${ }^{4} \mathrm{Klarman}$ Cell Observatory, Broad Institute of Massachusetts Institute of Technology (MIT) and Harvard, Cambridge, MA, USA 
Here, we examined the response of the spinal cord meningeal lymphocyte compartment to acute injury (spinal cord injury; SCI), as well as to chronic neurodegenerative conditions. We found that acute CNS injury is followed by formation of structures, reminiscent of TLS, within the spine meninges in close proximity to the lesion site. Such meningeal structures were found to be formed during the chronic phase of the response to acute injury, and mainly in the pia and dura mater. Meningeal TLS-like lymphocytes acquire an inflammatory phenotype, different from that observed in peripheral draining CLN. By using the mSOD1 mouse model of chronic spinal cord degeneration, often used as a model of amyotrophic lateral sclerosis (ALS), we found that lymphocytes isolated from spine meninges, but not from draining $C L N$, showed dynamic changes in lymphocyte activation, and specifically in B-cell differentiation (pre-B cells and plasma cells), along disease progression.

\section{Results}

\section{Immunological niche in the meninges after acute $\mathrm{SCI}$}

$\mathrm{SCl}$ induces an acute immune response in the injured parenchyma (Rolls et al, 2008; Shechter et al, 2009). When exploring the immune response within the lesion site $14 \mathrm{~d}$ after $\mathrm{SCl}$ (Raposo et al, 2014), we found aggregates of TCR $\beta^{+}$T cells in the spinal cord meninges, in close proximity to the primary injury site (Fig 1A). To fully understand the spatial organization of immune cells in the spinal cord meninges, we performed scanning electron microscopy (SEM) of the spinal cord parenchyma, together with the bones that envelop it. This technique enabled us to examine the meningeal tissue located between the spinal cord parenchyma and the bone, and to identify cells associated with these meningeal layers (Fig 1B). SEM images showed differences in cellular and matrix composition between meninges derived from uninjured spinal cords, compared with meninges isolated $14 \mathrm{~d}$ after $\mathrm{SCl}$. Scanning of the meninges at high magnification indicated that $\mathrm{SCl}$ induced the appearance of areas with fiber-like structures, compared to the smooth meningeal tissue in the uninjured animals (Fig 1C). Importantly, this structural feature of fiber-like meningeal components appeared together with leukocyte accumulation, specifically within meninges isolated from spinally injured mice (Fig 1C).

For quantitative characterization of the lymphocyte populations in the spinal cord meninges after $\mathrm{SCl}$, we first calibrated a tissue dissociation and cell purification technique for this tissue (see the Materials and Methods section). We then compared $\mathrm{CD}^{+} \mathrm{T}$ - and $\mathrm{B} 220^{+} \mathrm{B}$-cell frequencies between the meninges, the spinal cord parenchyma, and the peripheral cervical lymph nodes (cLN) (Fig 1D). We found that the lymphocyte composition in the spinal cord meninges was distinct from that observed within the injured parenchyma, and more closely related to CLN (Fig 1E). Whereas the lesion site of injured animals contained a majority of T cells (89\%, predominantly $\mathrm{CD}^{+} \mathrm{T}$ cells), in the adjacent meninges, as well as in the draining $C L N$, we found equal proportions of $B$ versus $T$ cells, and a similar ratio of $\mathrm{CD}^{+} / \mathrm{CD}^{-} \mathrm{T}$ cells (Fig $1 \mathrm{D}$ and $\mathrm{E}$ ). Next, we quantified the numbers of $\mathrm{CD}_{4} 5^{+}$leukocytes, $\mathrm{CD}^{+} \mathrm{T}$ cells, $\mathrm{B} 22 \mathrm{O}^{+} \mathrm{B}$ cells, and $\mathrm{CD}^{+} \mathrm{T}$ cells within a 6 - $\mathrm{mm}$ length of meningeal tissue, in close proximity to the lesion site, compared with distal regions in the spinal cord parenchyma, at day 14 after SCl (Fig 1F). We found that $\mathrm{SCl}$ induced the accumulation of $\mathrm{CD}_{4} 5^{+}$cells in general, and specifically of $\mathrm{B}$ and $\mathrm{T}$ cells, mainly of the $\mathrm{CD}^{+}$ subset, in a spatially restricted manner; the increase in lymphocyte numbers was observed in meningeal tissues that were isolated from areas in close proximity to the lesion site, and not from distal regions (Fig 1G). Taken together, these results suggest that during the late phase of the response to $\mathrm{SCl}$, a lymphocytedriven immune response develops in the adjacent meninges, characterized by a cLN-like immune cell composition.

\section{The meningeal immune response within its three anatomical layers}

The meninges are composed of three layers, the dura, arachnoid, and pia mater. Lymphocyte accumulation in the spinal cord meninges at the lesion site area after $\mathrm{SCl}$ raised the question of whether the meningeal immune response is uniform in all three layers, or whether any of the meningeal layers hosts a unique immunological niche. We performed a detailed analysis of the meningeal immune cell composition by microdissection of the dura, arachnoid, and pia spinal cord meningeal layers (Figs 2A and S1), and quantified the number of cell clusters (aggregates with more than 10 cells) over time after $\mathrm{SCl}$. Because the pia and dura layers were enriched with lymphocyte clusters, compared with arachnoid layer, during the chronic phase of the response to injury, we chose to further focus on these two layers.

To gain insight regarding the spatial aggregations and distribution of lymphocytes within the meningeal layers, we performed immunostaining of whole-mount dissected pia and dura mater. Under uninjured conditions, $\mathrm{CD}^{+} \mathrm{T}$ and $\mathrm{B} 220^{+} \mathrm{B}$ cells were abundant in the pia and dura mater, respectively, and were randomly distributed in the tissue, without any organized structures (Fig 2B). At day 14 after $\mathrm{SCl}$, in the meningeal tissue located in close proximity to the lesion site, we were able to detect the accumulation of lymphocyte aggregates and formation of large well-organized clusters in the pia and the dura mater (Fig 2C and D). We next quantified the lymphocyte composition in the clusters that were observed in the pia and dura mater. We found that in uninjured animals and at day 7 after $\mathrm{SCl}$, T cells were predominant in the pia, whereas B cells were enriched in the dura (Fig 2E). From day 14 onward, the late and chronic phase of response to $\mathrm{SCl}$, each layer contained clusters composed of heterogeneous lymphocyte populations (Fig 2E). Thus, the immune response in the meninges is spatially regulated and continues to evolve during the chronic phase of the response to acute insult. Overall, it appears that acute CNS insult induces deviation in lymphocyte composition within the different meningeal layers. Of note, we cannot rule out the possibility of some cross-contamination between layers during microdissection.

\section{Hallmarks of lymphogenesis factors present in the meninges after $\mathrm{SCl}$}

To understand the signaling that could potentially lead to lymphocyte accumulation at the meninges, we measured expression of factors associated with recruitment, accumulation, and induction of lymphocyte organization in non-lymphoid organs, such as the chemokines CXCL13, 
A TCR $\beta / d 14$

Spinal cord
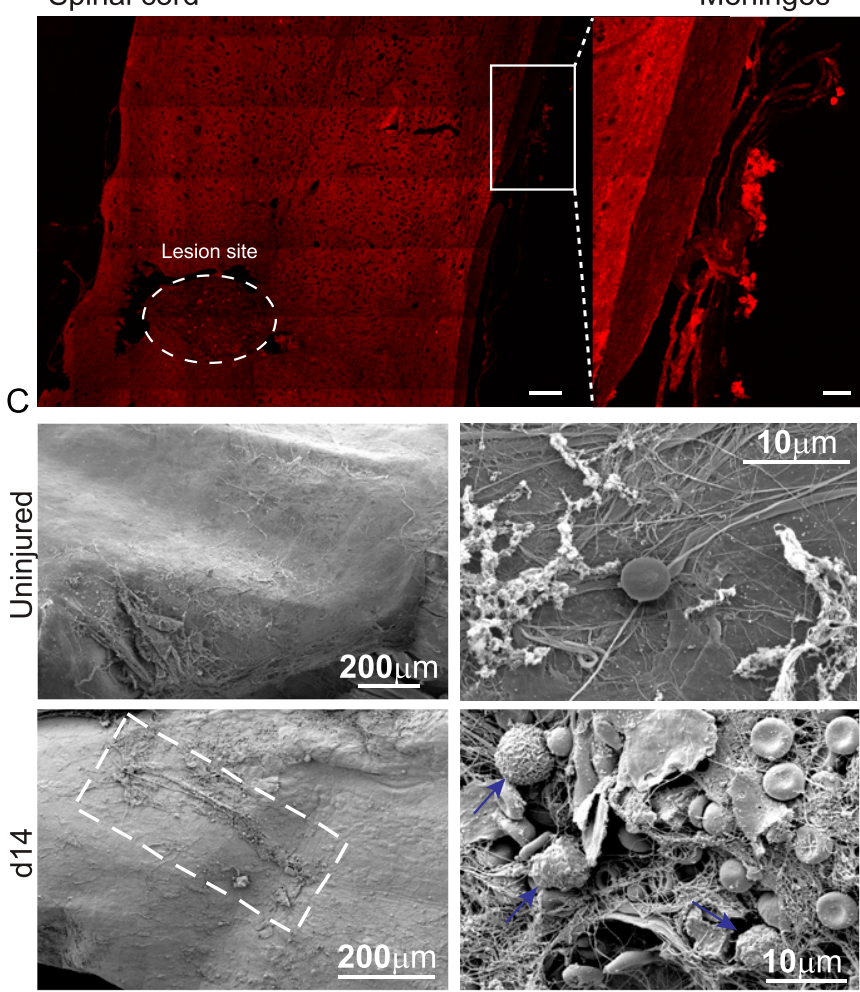

D Spinal cord

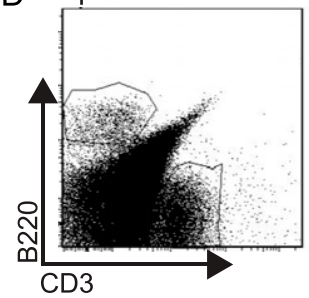

$\mathrm{cLN}$

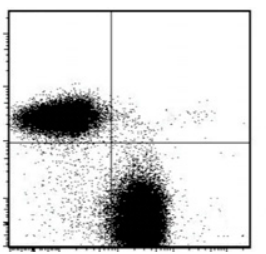

1

E

E Spinal cord
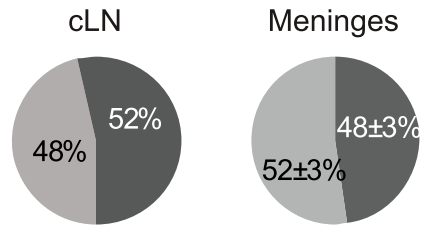

B220
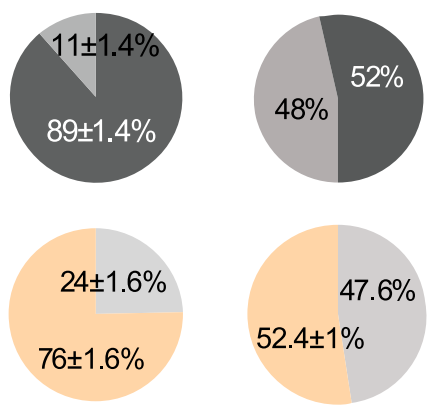

B

Spinal cord, meninges and bone/ d14
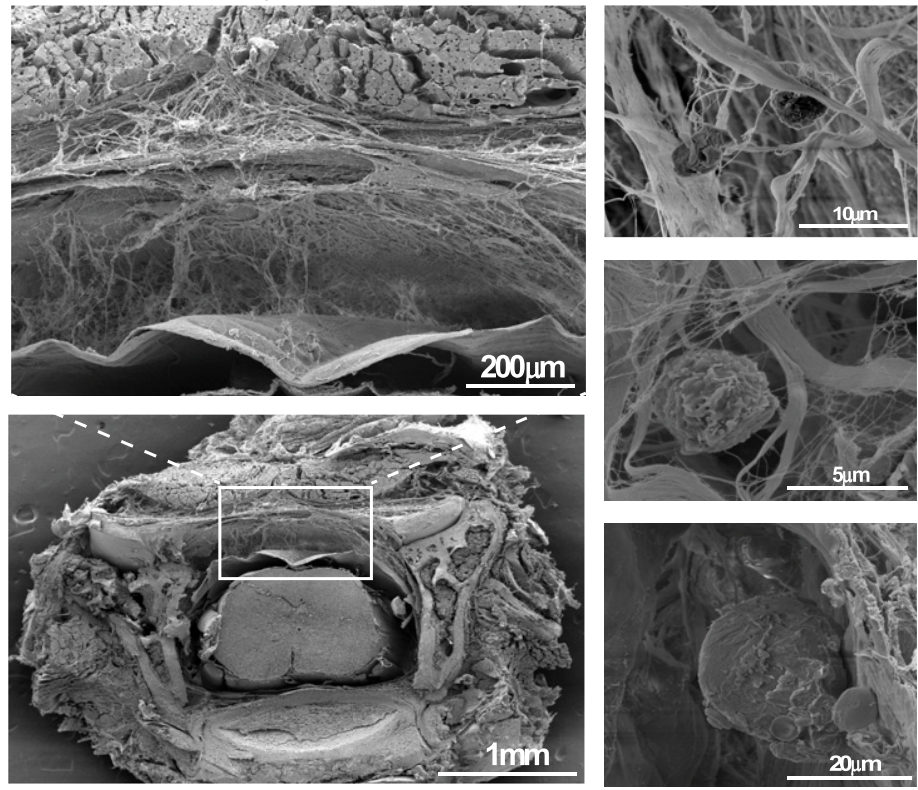

$\mathrm{F}$

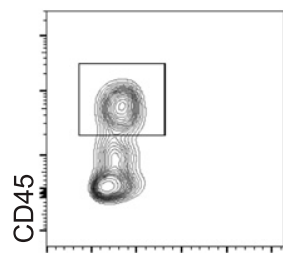

FSC
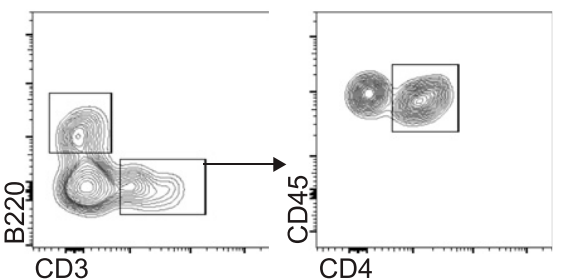
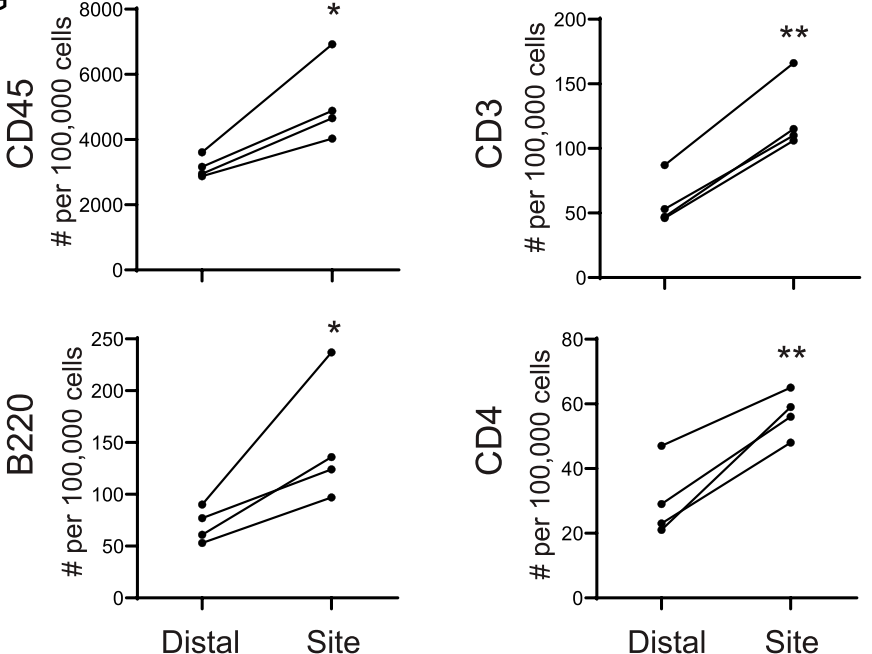

Figure 1. Lymphocyte aggregation in the spinal cord meninges after spinal cord injury (SCI).

(A) Representative immunofluorescent staining of TCR $\beta^{+}$cells in the spinal cord parenchyma and the adjacent meninges $14 \mathrm{~d}$ following SCl; scale bar: $100,20 \mu \mathrm{m}$ inset. (B) Transverse scanning electron microscopy image of spinal cord including the bone $14 \mathrm{~d}$ after SCl, showing separation of meningeal layers and the presence of cells on the meninges. (C) Scanning electron microscopy images of spinal cord meninges derived from uninjured animals (upper panel) and at day 14 after SCl (lower panel), taken at different magnifications. (D) Representative flow cytometry plots demonstrating the composition of B and T cells at the spinal cord parenchyma, draining cervical lymph node, and spinal cord meninges. $n=4$; each sample represents a pool of two animals. (E) Flow cytometry quantification of T and B cell ratio out of total lymphocytes (upper panel), and of $\mathrm{CD}^{+}$and $\mathrm{CD}^{-}$out of total T cells (lower panel) in the spinal cord parenchyma, cervical lymph node and spinal cord meninges at day 14 following SCl. $\mathrm{n}=4$; each sample represents a pool of two animals. Data shown are representative of at least three independent experiments. (F) Representative flow cytometry plots demonstrating the gating strategy for characterization of the leukocyte and lymphocyte populations in the spinal cord meninges. $n=4$; each sample represents a pool of 
CCL21, CCL19, and proteins related to the lymphotoxin (LT) pathway (Kratz et al, 1996; Fan et al, 2000; Amft et al, 2001; Shi et al, 2001). Using quantitative RT-PCR (qRT-PCR) analysis of the pooled meningeal tissue at different time points after $\mathrm{SCl}$, we found increased expression of several of these molecules, including CCl21, lymphotoxin- $\alpha(L t \alpha)$, and lymphotoxin- $\beta(L t \beta)$, and their corresponding receptors ( $C c r 7$ and $L t \beta r$ ), at the late phase of the response to injury (days 14 and 19), relative to the meninges of uninjured animals (Fig 3A). In addition, using wholemount immunostaining, we found that some of these molecules, such as CCL21, were associated with $\mathrm{CD}_{3} 1^{+}$endothelium in the brain meninges during homeostasis, and also following $\mathrm{SCl}$ (Fig 3B). In the spinal cord meninges, we identified the expression of CCL21 (Fig 3C), and of the lymphatic vessel marker, LYVE-1, next to $\mathrm{CD} 31^{+} \mathrm{CD} 34^{+}$endothelial cells in the pia (Fig 3D) and the dura (Fig $3 \mathrm{E})$ mater $14 \mathrm{~d}$ after $\mathrm{SCI}$. These results provide an evidence of an infrastructure which can support lymphocyte homing to the meningeal layers following CNS insult (Baluk \& McDonald, 2008; Mueller \& Germain, 2009). In addition, in the dura mater, we also found areas of high immunoreactivity of the $B$ cell chemokine CXCL13, associated with clusters of B cells (Fig 3F). Notably, the presence of the chemokine CXCL13 in the dura mater is in line with the observations that the dura compartment is more closely associated with a B-cell response (Fig $2 \mathrm{~B}$ and $\mathrm{E}$ ). We quantified the number of B-cell clusters co-localized with CXCL13 at the acute (7 d after $\mathrm{SCl}$ ) and chronic phases (day 14 and 21 after $\mathrm{SCl}$ ), and found an increase in these clusters during the late stages of the response to injury (Fig 3G). Notably, CXCL13, like CCL21, was also detected in the dura mater of uninjured mice (Fig 3A), but without co-localization with B-cell aggregates, suggesting that in homeostasis, the meninges are endowed with an infrastructure that enables signaling for lymphoid niche formation upon need; however, formation of lymphocyte aggregates is a consequence of multiple signals.

\section{Meningeal lymphocyte structures are reminiscent of SLOs}

Our results showed that the immune response occurring in the spinal cord meninges is initiated by the homing of lymphocytes to an area located in close proximity to the lesion site. To further characterize the immune fate of these meningeal lymphocyte clusters, we sorted $\mathrm{B}_{2} 2 \mathrm{O}^{+} \mathrm{B}$ and $\mathrm{CD}^{+} \mathrm{T}$ cells from the meninges adjacent to the lesion site and compared their cytokine and transcription factor gene expression profiles to those of lymphocytes derived from the CNS-draining CLN, $14 \mathrm{~d}$ after $\mathrm{SCl}$. We found that meningeal B cells expressed genes related to plasma cell development and differentiation, such as Pax5, Irf4, and Xbp1 (Nutt et al, 2015), similar to B cells isolated from CLN (Fig 4A). Interestingly, meningeal $B$ cells exhibited a strong plasma cell response $\left(\mathrm{Xbp}^{\text {high }}\right)$, and a pro-inflammatory activation state characterized by expression of genes related to CNS inflammation and autoimmunity, including Il6, Ifny, Ifnyr, Il23, and Tnfa (Harris et al, 2000, 2005; Duddy et al, 2007; Barr et al, 2012). This plasma cell response and pro- inflammatory phenotype were attenuated and absent, respectively, in B cells isolated from CLN (Fig 4A). Meningeal $\mathrm{CD}^{+} \mathrm{T}$ cells showed high heterogeneity in cellular phenotype, exhibiting increased gene expression of regulatory (Foxp3 and Il10), Th1 (Tbx21 and Ifny), and encephalitogenic (Rorc, 116 , and Tnfa) (Korn et al, 2008) markers. As was shown for the B-cell compartment, the expression of $\mathrm{CD}^{+} \mathrm{T}$-cell immune activation genes was restricted to the spine meninges, and absent from the peripheral CLN (Fig 4A).

$\mathrm{GC}$ is a defining marker of $\mathrm{B}$ cell clusters, and a fundamental characteristic of any SLO. GC can be formed ectopically and are found under conditions of chronic inflammation as part of a local lymphoid organization, termed TLS (Schroder et al, 1996; Luther et al, 2000; Shi et al, 2001; Moyron-Quiroz et al, 2004; Serafini et al, 2004; Grabner et al, 2009; Shields et al, 2010; von Budingen et al, 2015). We, therefore, evaluated the maturation state of the meningeal $\mathrm{B}$-cell population after $\mathrm{SCl}$, to detect the possible presence of GC. We found that meningeal $B$ cells derived from both uninjured and injured animals consisted of both B220 high and B220 low populations (Fig 4B). Interestingly, the non-conventional B220 ${ }^{\text {low }}$ subset, which was shown to mainly include cells mediating an antibody response (Kawabe et al, 2004; Tachikawa et al, 2008; Fujii et al, 2010), was the most abundant in the lesion site meninges and showed the strongest induction after $\mathrm{SCl}$ (Fig 4B). Using immunostaining, we identified IgD ${ }^{+}$and $I g M^{+} B$ cells in the meninges of injured mice (Fig $4 \mathrm{C}$ and $\mathrm{D}$ ). Moreover, flow cytometry analysis of lesion site meninges at day 14 after $\mathrm{SCl}$ revealed the presence of $\mathrm{B}$ cells at different stages of isotype switching. The mature but naive state, characterized by $\operatorname{lgM}^{+} \operatorname{IgD}{ }^{+} \mathrm{B}$ cells (Dalakas, 2008), was derived from the $B 220^{\text {high }} B$ cells, whereas $B 220^{\text {low }}$ cells were all IgD', including both $\mathrm{IgM}^{+}$and $\mathrm{IgM}^{-}$cells, reflecting mature and more activated states (Fig 4E). In addition, we found that as a result of $\mathrm{SCl}$, the meningeal $B$ cells, mainly the B220 low population, expressed the $\mathrm{GC}$ activation markers peanut agglutinin (PNA) and GL7 (Fig 4F).

An important feature of an active lymphoid site is expansion of lymphocyte clones, in association with antigen presentation. We identified proliferating $\mathrm{Ki} \mathrm{7}^{+} \mathrm{B}$ cells, in close proximity to nonproliferating ones within the same cluster, $14 \mathrm{~d}$ after SCI (Fig 4G). Moreover, bromodeoxyuridine (BrdU) injection to spinally injured mice, 12 and $1 \mathrm{~h}$ before their meninges were excised, showed that most $\mathrm{CD}^{+} \mathrm{T}$ cells at the meninges were in a proliferative state, incorporating BrdU, with only a few non-proliferating cells (Fig $4 \mathrm{H}$ ). Notably, we found that the meningeal lymphocyte clusters were

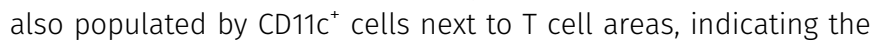
occurrence of possible immunological synapses between DC and T cells within the meningeal lymphocyte structures (Fig 4l); such interactions could drive the proliferation of the T cells, an important feature of LN immune surveillance.

We further analyzed the phenotype of the meningeal T cells and compared it with that of T cells in the CNS-draining CLN. Analysis of the meningeal $\mathrm{CD}^{+} \mathrm{T}$ cells at day 14 after $\mathrm{SCl}$ revealed that $\mathrm{CD} 44^{\text {high }}$ memory $T$ cells predominated in the meningeal lymphocyte structures ( $87 \%$ of $C D 4^{+} \mathrm{TCR} \beta^{+}$cells), while this memory population was diminished in $\mathrm{CLN}\left(21 \%\right.$ of $\mathrm{CD}^{+}{ }^{+} \mathrm{TCR} \beta^{+}$cells; Fig 4$)$ ). Importantly, the majority of memory $T$ cells in the meningeal lymphoid structures lost

two animals. (G) Flow cytometry quantification of leukocytes and lymphocyte populations present at the lesion site meninges versus those located distally to the lesion site; each sample represents pooled tissue from two animals. ${ }^{*} P<0.05$. ${ }^{* *} P<0.01$. Data are presented as mean \pm SEM. 
A

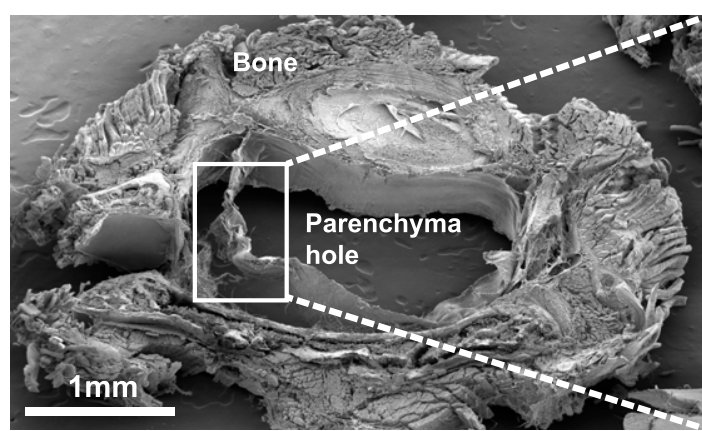

B

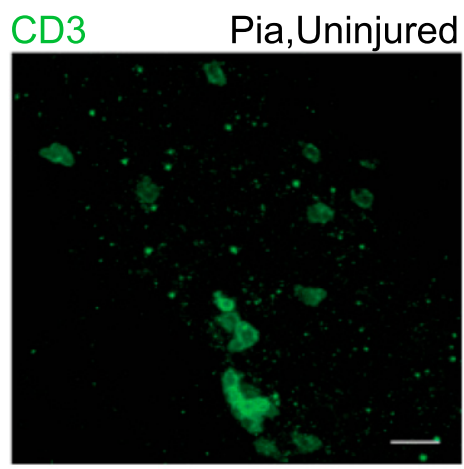

D

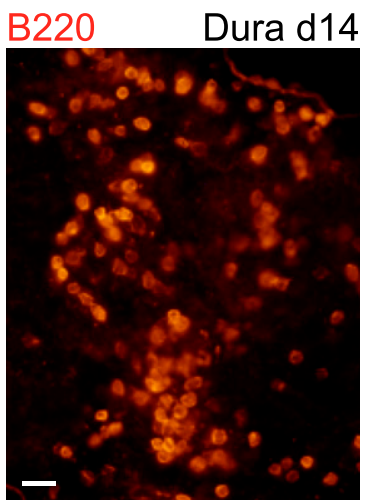

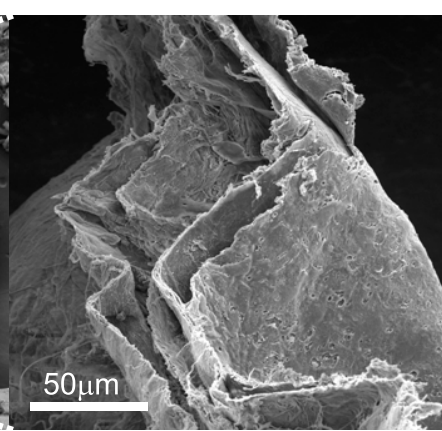

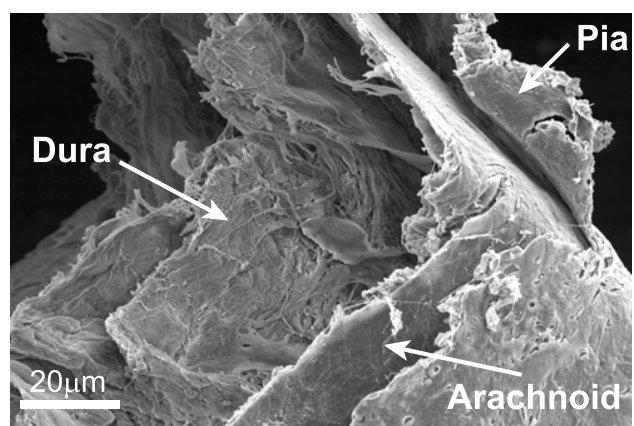

C
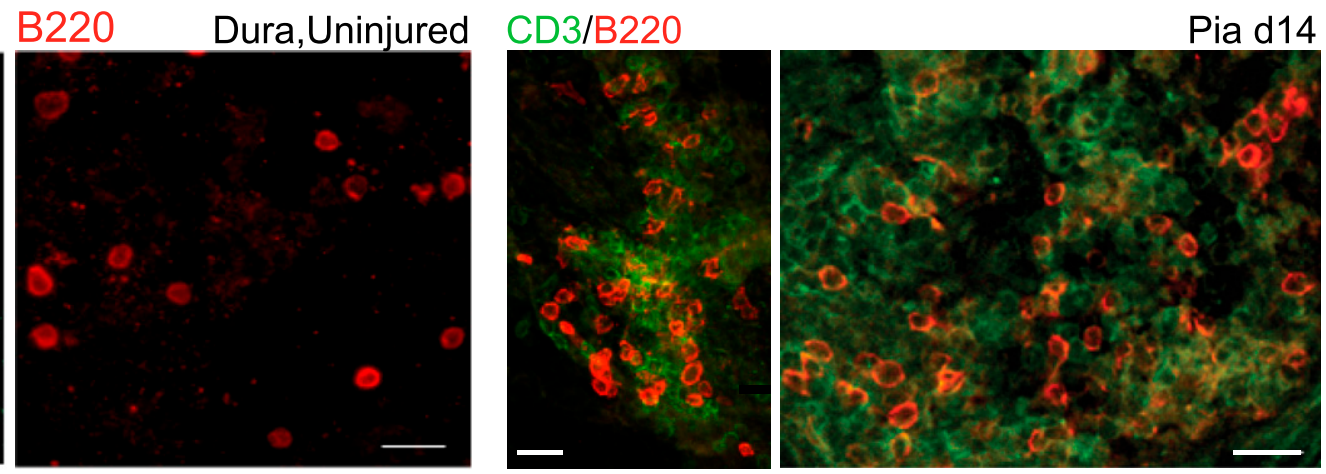

E
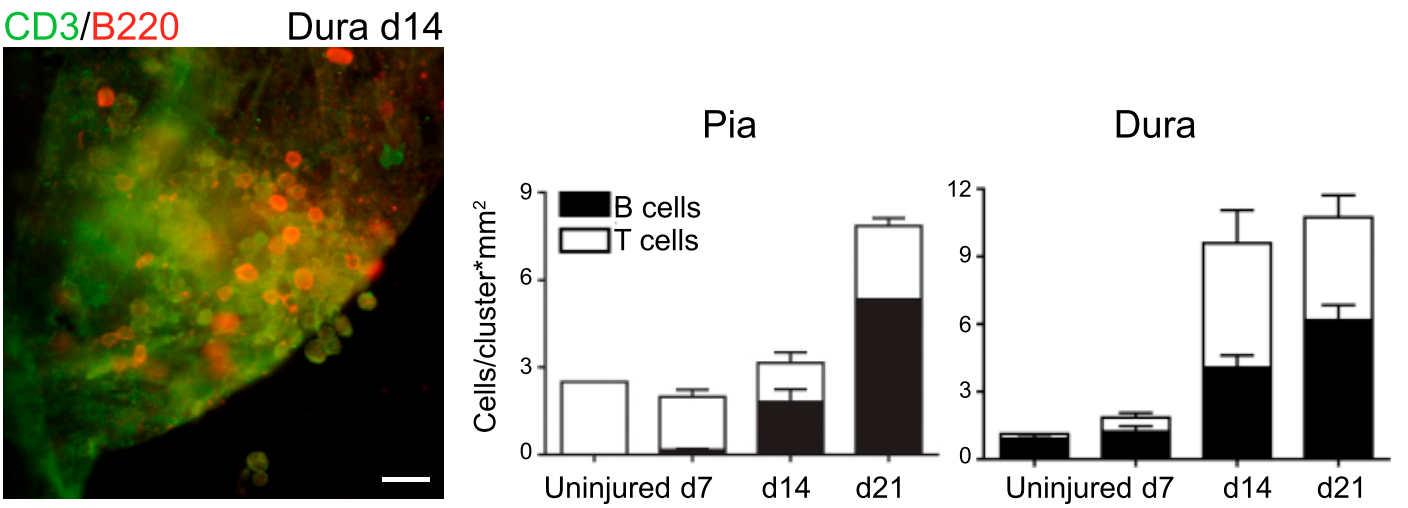

Figure 2. Segregation of the meningeal lymphocyte niche into the anatomical layers.

(A) Representative scanning electron microscopy (SEM) images showing separation of the three spinal cord meningeal layers. (B) Representative immunofluorescent whole-mount staining of the spinal cord pia and dura meningeal layers, for T cells and B cells under uninjured conditions. Scale bar: $20 \mu$ m. (C, D) Representative immunofluorescent whole-mount staining of the pia (C), and dura (D) meningeal B- and T-cell clusters at d 14 after SCl. Scale bar; $50 \mu$ m. (E) Whole-mount quantification of the number of B cells (black) or T cells (white) in each cluster present at the pia and dura layers of uninjured mice, and along different time points following SCl. (E) Results are pooled from three animals at each time point, and normalized to the indicated area.

the expression of L-selectin, and therefore exhibited a phenotype of effector-like memory T cells (76\%; CD44 ${ }^{\text {high }} \mathrm{CD} 62 \mathrm{~L}^{\text {low }}$ ), whereas only $11 \%$ were central-like memory $T$ cells $\left(C D 44^{\text {high }}{ }^{C D 62} L^{\text {high }}\right)$. Interestingly, in CLN, $\mathrm{CD}_{4} 4^{+} \mathrm{T}$ cells comprised equal proportions of $\mathrm{T}$ effectorlike and T central-like memory cells (Fig 4J)). Overall, T-effector memory cells represented $76 \%$ of the total meningeal $\mathrm{CD}^{+} \mathrm{T}$ cells, compared with $40 \%$ found in the adjacent injured parenchyma (Raposo et al, 2014). Thus, we observed that spinal cord meninges harbor a unique lymphoid niche after injury, at a specific spatial location relative to the lesion site. The particular features of the meningeal lymphocyte clusters, including their gene expression profile, presence of B cells with GC features, proliferation of T lymphocytes and their co-localization with $\mathrm{CD}_{11 C^{+}} \mathrm{DC}$, enrichment of effector-like memory $T$ cells, and the fact that these clusters showed a stronger immune activation state than the peripheral CLN following $\mathrm{SCl}$, led us to define them as meningeal TLS. 
A

\begin{tabular}{lcccc} 
& Uninjured & $\mathrm{d} 14$ & $\mathrm{~d} 19$ & $\mathrm{P}_{\text {value }}$ \\
\hline Lymphotoxin $\alpha$ & $121 \pm 77$ & $209 \pm 61$ & $374 \pm 213$ & 0.43 \\
Lymphotoxin $\beta$ & $39 \pm 0.6$ & $59 \pm 11$ & $203 \pm 50$ & $0.01^{*}$ \\
Lymphotoxin $\beta$ receptor & $97 \pm 10$ & $33 \pm 19$ & $178 \pm 36$ & $0.005^{\star *}$ \\
Ccl21 & $31 \pm 4$ & $53 \pm 12$ & $75 \pm 19$ & 0.19 \\
Cxcl13 & $55 \pm 11$ & $61 \pm 41$ & $52 \pm 22$ & 0.54 \\
Bcl6 & $24 \pm 6$ & $24 \pm 12$ & $32 \pm 10$ & 0.89 \\
Ccr7 & $17 \pm 4$ & $43 \pm 3$ & $75 \pm 14$ & $0.01^{*}$ \\
\hline
\end{tabular}

\section{B CD31/CCL21}

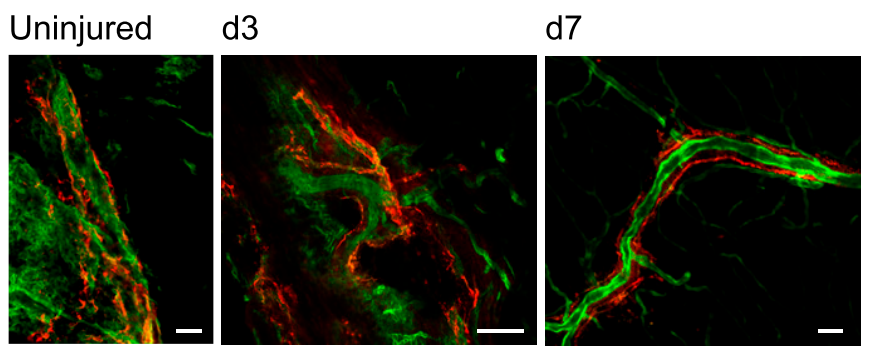

\section{ERTR7/CCL21}

\section{d14}

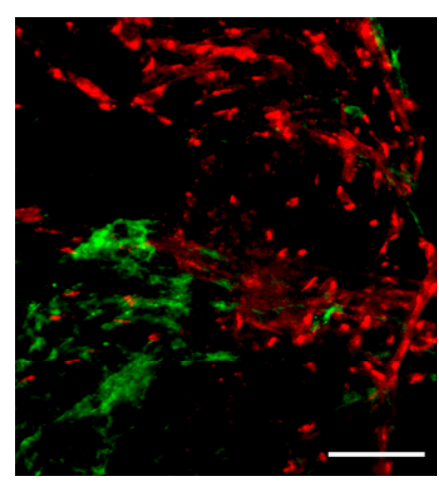

\section{DLYVE-1/CD31\&CD34}

\section{Pia d14}

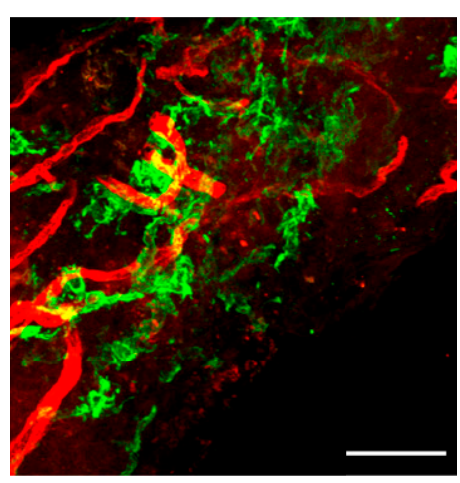

Pia d14

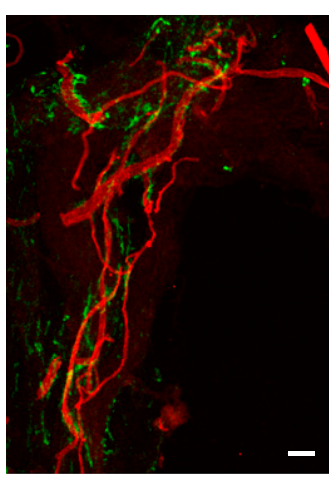

E LYVE-1/CD31\&CD34

Dura d14

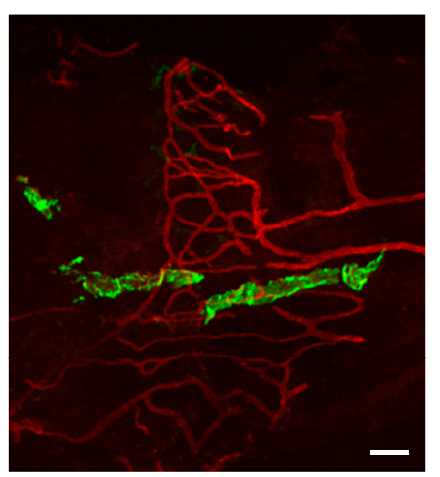

\section{F B220/CXCL13}

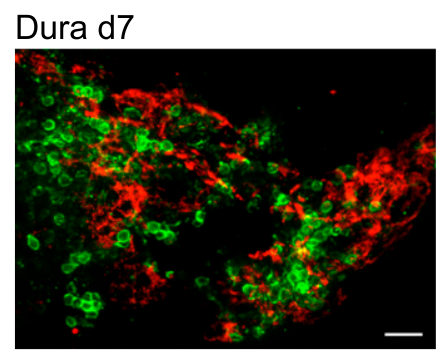

G

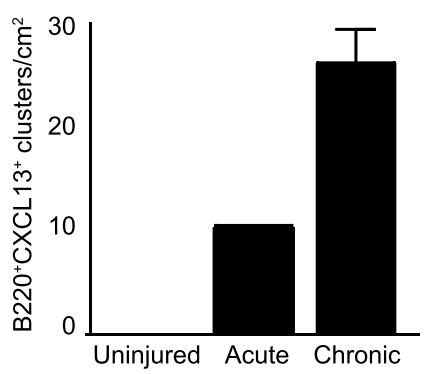

Figure 3. Presence of lymphogenesis factors in the spinal cord meninges.

(A) Gene expression evaluation of lymphogenesis factors in spinal cord meninges adjacent to the injury site, at different time points after the insult, and in uninjured mice,

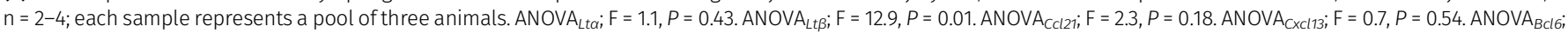

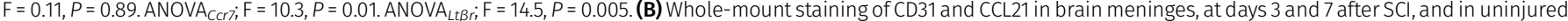
mice. Uninjured and day 3 sections: scale bar; $50 \mu \mathrm{m}$; day 7 section: scale bar; $100 \mu \mathrm{m}$. (C) Immunofluorescent whole-mount staining of spinal cord meninges $14 \mathrm{~d}$ after $\mathrm{SCl}$ for reticular fibroblasts (ERTR7) and the T-cell chemoattractant molecule, CCL21. Scale bar: $50 \mu \mathrm{m}$. (D, E) Immunofluorescent whole-mount staining of spinal cord meninges $14 \mathrm{~d}$ after SCI for lymphatic vessels (LYVE-1) and endothelium (CD31, CD34) in the pia (D), and the dura (E). Scale bar; $50 \mu \mathrm{m}$. (F, G) Immunofluorescent whole-mount staining of dura mater at $\mathrm{d} 7$ after $\mathrm{SCI}$ for B220+ B cells, and for the B cell-associated chemokine, CXCL13, and (G) quantification of the number of co-localized B cell clusters with CXCL13 expression, under uninjured conditions, and at acute (day 7 after $\mathrm{SCl}$ ) and chronic (days 14 and 21 after $\mathrm{SCl}$ ) phases of the response to the injury. Results are pooled from three animals at each time point, and normalized to the tissue area. Scale bar; $50 \mu \mathrm{m}$. Asterisk in (A) indicates statistically significant differences after ANOVA post-hoc analysis using Tukey's honestly significant difference $\left({ }^{*}\right.$, relative to uninjured; ${ }^{* *}$ in $L T \beta r$, relative to d 14 after SCI) ${ }^{*} P<0.05 .{ }^{* *} P<0.01$. Data are presented as mean \pm SEM.

\section{Impact of meningeal TLS on CNS pathologies}

Based on our results, we hypothesized that the meningeal TLS might play a role in chronic CNS pathologies in which inflammation is part of the disease etiology. To test this possibility, we examined the meningeal immune response under the inflammatory condition, EAE. We immunized mice with the encephalitogenic peptide (35-55) derived from myelin oligodendrocyte glycoprotein (MOG), and analyzed the inflammatory and encephalitogenic state of the meningeal lymphocytes under three different conditions: $14 \mathrm{~d}$ after SCI (SCI), $14 \mathrm{~d}$ after EAE induction (EAE), and 14 
A

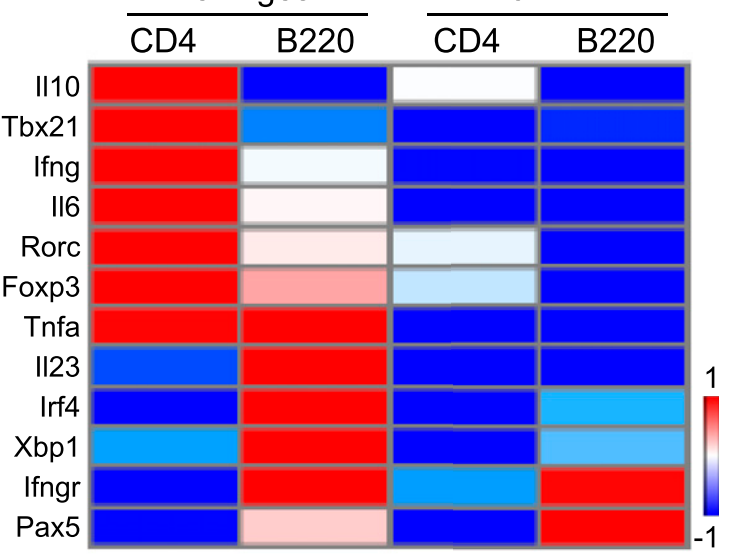

E

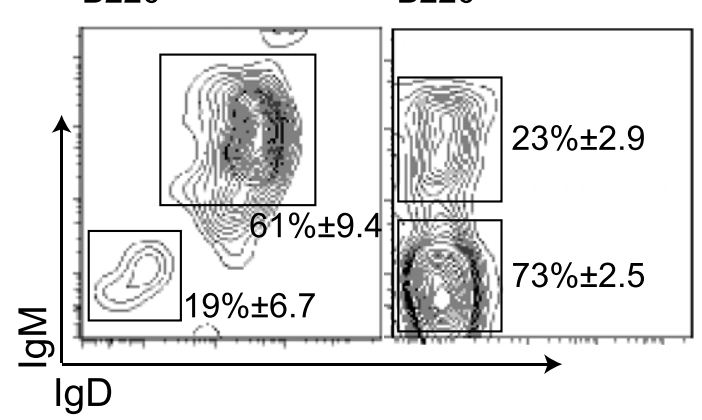

B

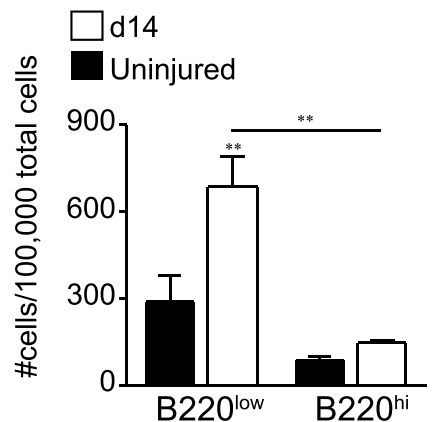

F

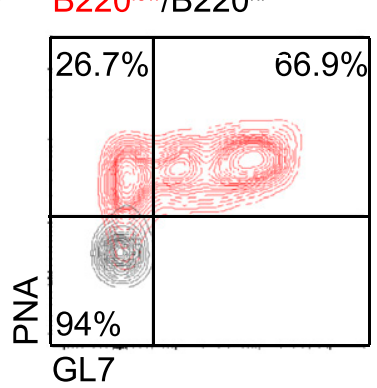

C

B220/lgD

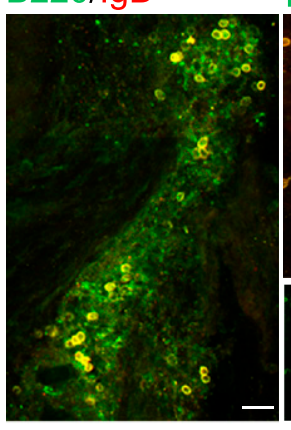

B220/lgM

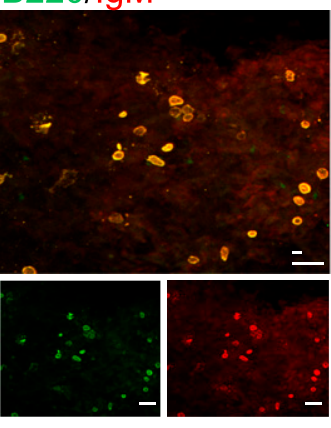

G

B220/KI67

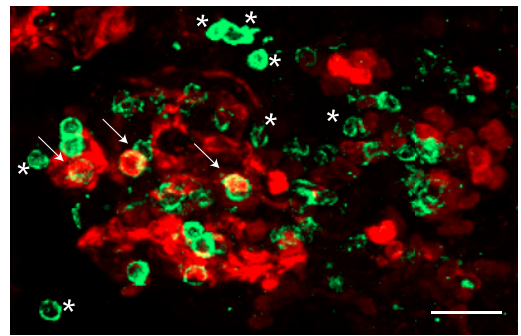

$\mathrm{H}$

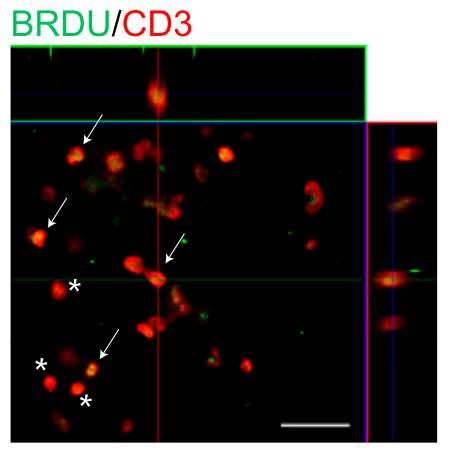

I

CD11C/CD3

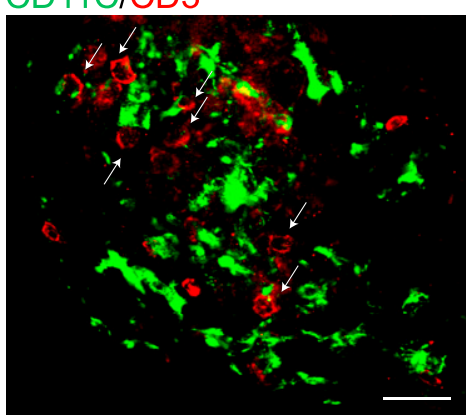

J

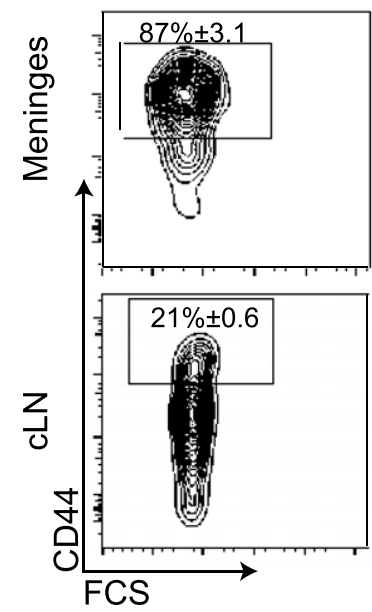

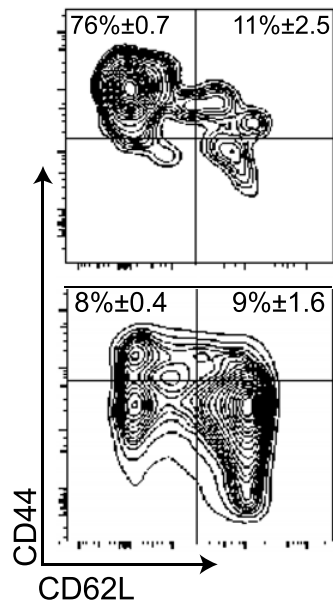

Figure 4. Meningeal lymphocytes are activated and share features of tertiary lymphoid structures.

(A) Gene expression analysis of isolated $\mathrm{B}_{22} \mathrm{O}^{+} \mathrm{B}$ and $\mathrm{CD}_{4}{ }^{\top} \mathrm{T}$ cells, from the spinal cord meninges and cervical lymph node $14 \mathrm{~d}$ after $\mathrm{SCl}$, for evaluation of cytokines and transcription factors associated with inflammation and lymphocyte activation. Tissues from 20 animals were pooled; data shown are representative of two independent experiments; red and blue indicate high and low relative expression, respectively. (B) Quantification of B220 ${ }^{\text {low }}$ and B220 high cells at the meninges in uninjured animals (black) and at day 14 after SCI (white); $n=2-4$; each sample represents a pool of four animals. Data shown are representative of four independent experiments. (C, D) Immunofluorescent whole-mount staining of spinal cord meninges for IgD ${ }^{+}$(C), and IgM ${ }^{+}$(D) B cells at d 14 after SCI. Scale bar; $50 \mu \mathrm{m}$. (E) Flow cytometry plots indicating

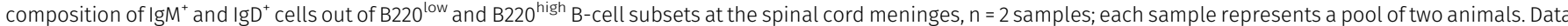
shown are representative of two independent experiments. (F) Density flow cytometry plot demonstrating the presence of PNA ${ }^{+} G L 7^{+} G C B$ cells at the meninges at $d 14$ after SCl. Meningeal tissues were pooled from four animals. (G) Representative immunofluorescent whole-mount staining at d 14 after SCl, of dura mater samples for proliferating Ki67 ${ }^{+}$cells and B cells. Asterisks indicate non-proliferating B cells. Scale bar; $50 \mu \mathrm{m}$. (H) Representative immunofluorescent whole-mount staining of meninges, demonstrating the proliferating $\mathrm{BrdU}^{+} \mathrm{CD}^{+} \mathrm{T}$ cells. Asterisks indicate non-proliferating T cells. Scale bar; $50 \mu \mathrm{m}$. (I) Representative immunofluorescent wholemount staining of meningeal CD11 $\mathrm{C}^{+} \mathrm{DC}$ in close proximity to $\mathrm{CD} 3^{+} \mathrm{T}$ cells at d 14 after SCl. Scale bar; $50 \mu \mathrm{m}$. (J) Flow cytometry density plots of $\mathrm{CD} 4^{+} \mathrm{T}$ cells isolated from cLN and meninges adjacent to the lesion site $14 \mathrm{~d}$ after SCl, comparing the composition of CD44 high memory T cells, and the subpopulations of central-like and effector-like memory T cells. Results are representative of two experiments, $n=2$; each sample represents a pool of four animals. ${ }^{* \star} P<0.01$; Data are presented as mean $\pm S E M$. 
$\mathrm{d}$ after EAE induced $14 \mathrm{~d}$ after $\mathrm{SCI}$ (SCI+EAE) (Fig 5A). Induction of EAE, a condition in which the T-cell parenchymal response has been characterized in detail, induced an enhanced accumulation of T lymphocytes in the spinal cord meninges, compared with meninges of mice that were subjected to $\mathrm{SCl}$ alone, whereas the meningeal $\mathrm{B}$-cell niche was unchanged (Fig 5B). Importantly, meninges of mice that were spinally injured and then injected with MOG peptide for EAE induction $(\mathrm{SCl}+\mathrm{EAE})$, at a time when there was a well-formed TLS following the injury, exhibited increased accumulation of both $B$ and $T$ lymphocytes (Fig 5B). Gene expression analysis of $\mathrm{T}$ and $\mathrm{B}$ lymphocytes isolated from the spinal cord meninges under the three conditions revealed $\mathrm{a}$ general trend of higher encephalitogenic Th17 response (e.g., Rorc, II17a, Irf4, Pdpn, Il17ra, and Il6) (Brustle et al, 2007) in the meninges of mice subjected to $\mathrm{SCl}+\mathrm{EAE}$, relative to lymphocytes isolated from meninges of mice subjected to $\mathrm{SCl}$ or EAE alone (Fig 5C and D).

\section{Meningeal lymphocytes are activated in a model of ALS}

Based on the above results and to examine to what extent the observed phenomenon of meningeal TLS is also an outcome of chronic neurodegenerative spinal cord pathologies that are not inflammatory in etiology, we used an animal model of ALS. Specifically, we used a transgenic mouse model for ALS, bearing a mutation in the ubiquitously expressed Cu-Zn superoxide dismutase (SOD1), and isolated all T and B lymphocytes from their spinal cord meninges at four stages of disease progression $(92,106$, 136 , and $161 \mathrm{~d}$ ). Disease progression was associated with a decrease in body weight of mSOD1 mice (Fig S2A).

To thoroughly characterize the gene expression profile of different lymphocyte subsets derived from the spinal cord meninges, relative to CNS-draining CLN along disease progression, we recalibrated the protocol for dissociation of the meningeal tissue (see the Materials and Methods section), and sorted $B$ and $T$ lymphocytes (Fig S2B) to perform massively parallel single-cell RNA-sequencing (MARS-seq) (Keren-Shaul et al, 2019). We profiled $1051 \mathrm{~B}_{2} 20^{+} \mathrm{B}$ cells and $946 \mathrm{CD}^{+} \mathrm{T}$ cells from the meninges and CLN of 16 SOD1 mice and used the MetaCell algorithm to identify homogeneous and robust groups of cells ("metacells") (Baran et al, 2019). A heat-map representation of single-cell gene expression profiles revealed a clear separation between $B$ and $T$ lineages, and $a$ subdivision of the cells into diverse cell subsets (Fig 6A). In the $\mathrm{T}$-cell compartment, we identified $\mathrm{CCl}^{+} \mathrm{T}$ cells (characterized by
A

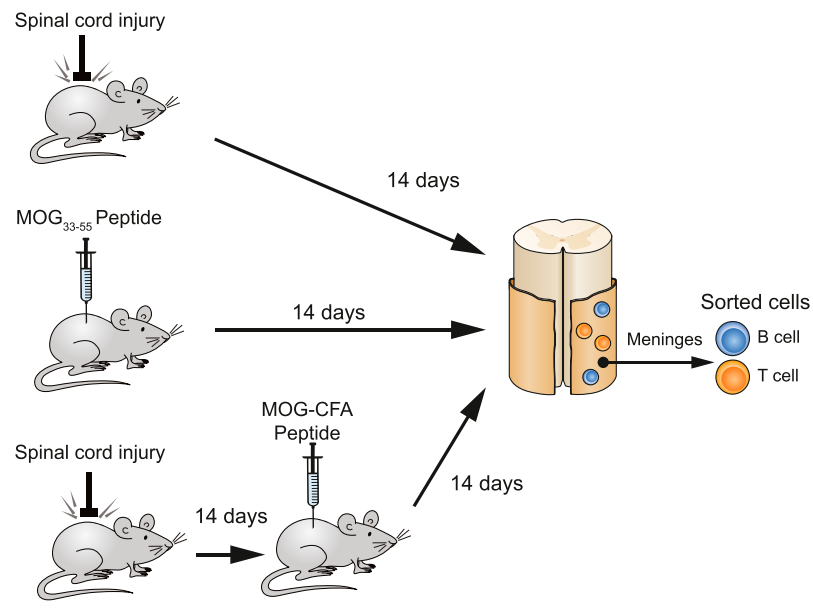

B

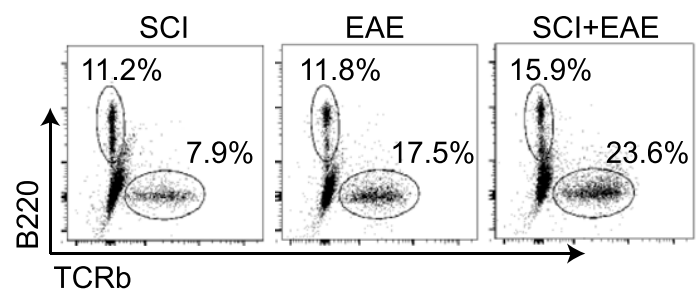

C

Rorc

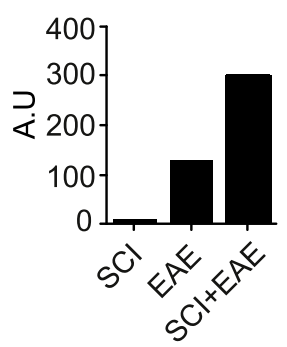

II17a

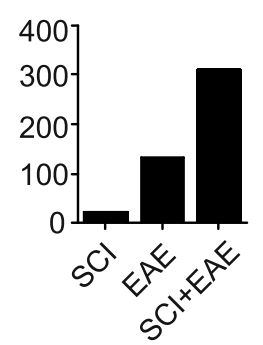

Irf4

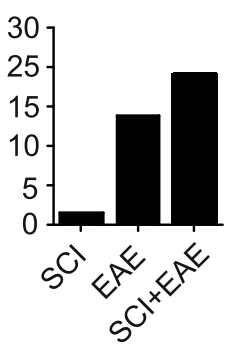

Pdpn

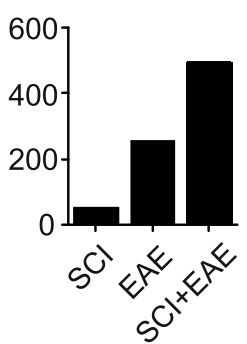

II17ra

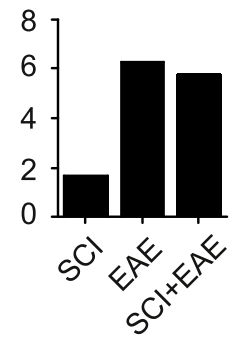

116

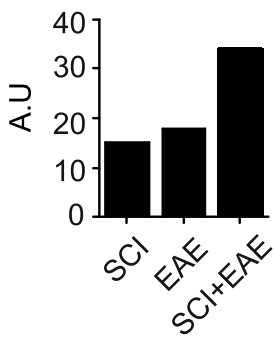

Figure 5. Meningeal TLS following spinal cord injury affects the spine meminges inflammatory response occurring in EAE pathology.

(A) A scheme depicting the experimental design of Myelin Oligodendrocyte Glycoprotein (MOG) immunization after SCI. Naïve WT mice (EAE), or mice $14 \mathrm{~d}$ after SCI (SCI+EAE) were immunized with the encephalitogenic MOG peptide. Animals subjected to SCI-only served as controls (SCI); cells were sorted by fluorescence activated cell sorting $14 \mathrm{~d}$ after MOG immunization, or after SCI (controls). (B) Flow cytometry plots showing TCR $\beta^{+}$T cells and B220 ${ }^{+} \mathrm{B}$ cells isolated from spinal cord meninges under the different conditions detailed in (A). (C, D) qRT-PCR results for selected genes expressed by meningeal CD4 ${ }^{+} \mathrm{T}$ cells (C), and B220 B cells (D) derived from spinal cord meninges under the different conditions detailed in (A). Each condition represents a pool of 10 mice. 


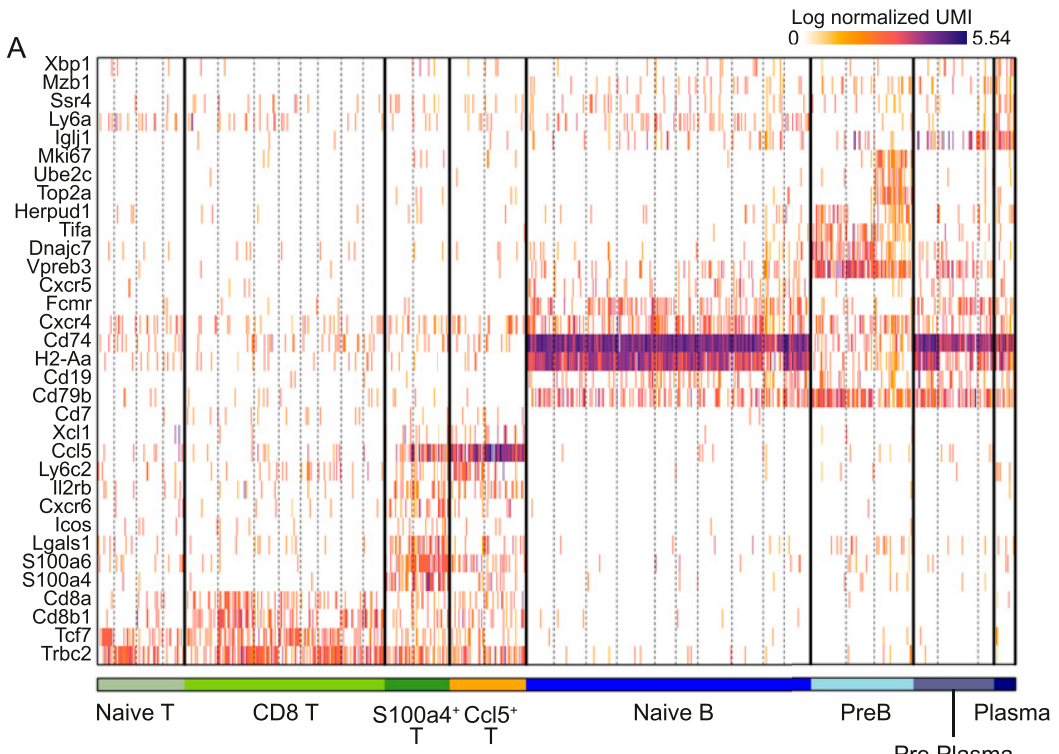

B
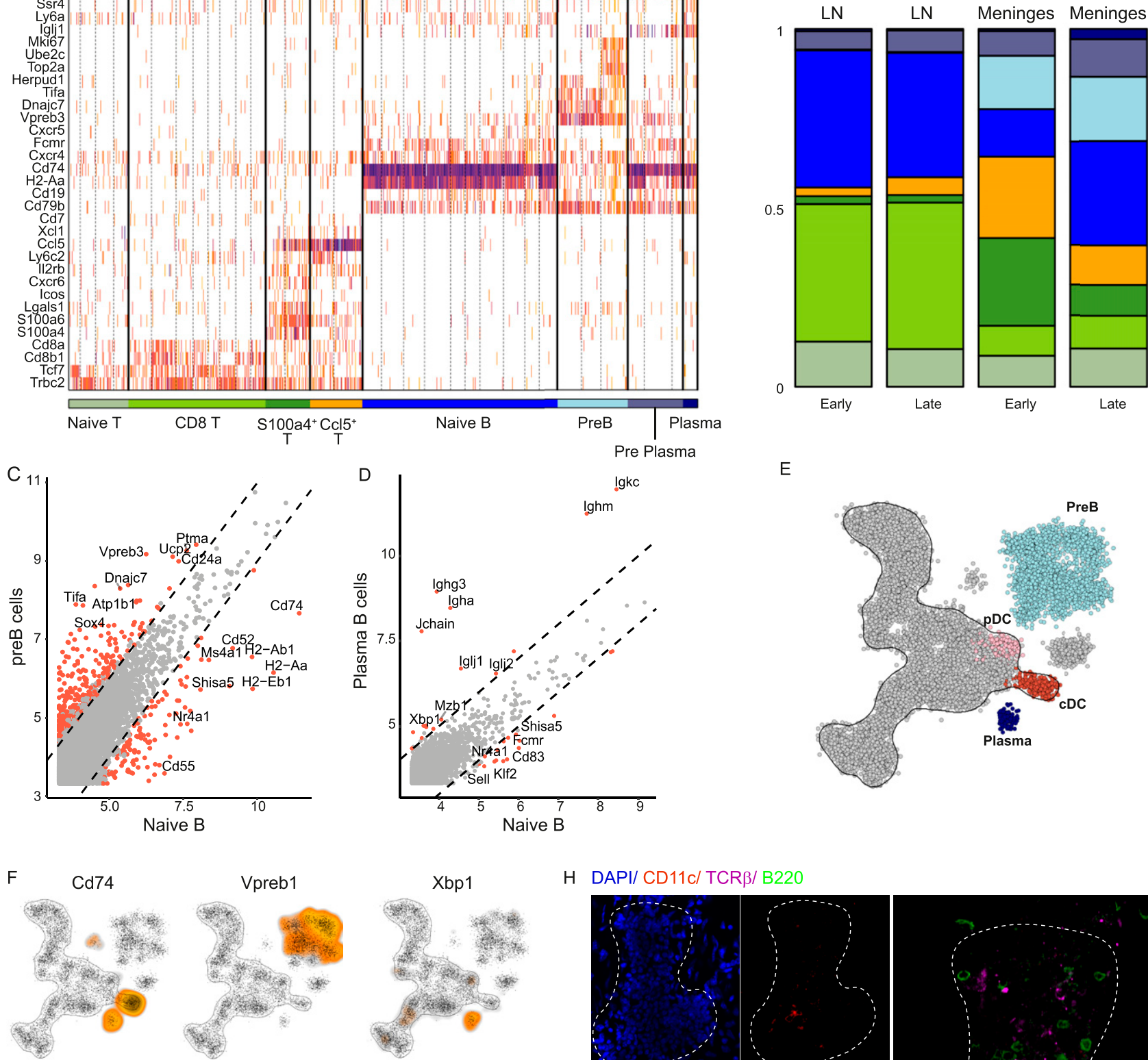

H DAPI/ CD11c/ TCRß/ B220

G

PreB
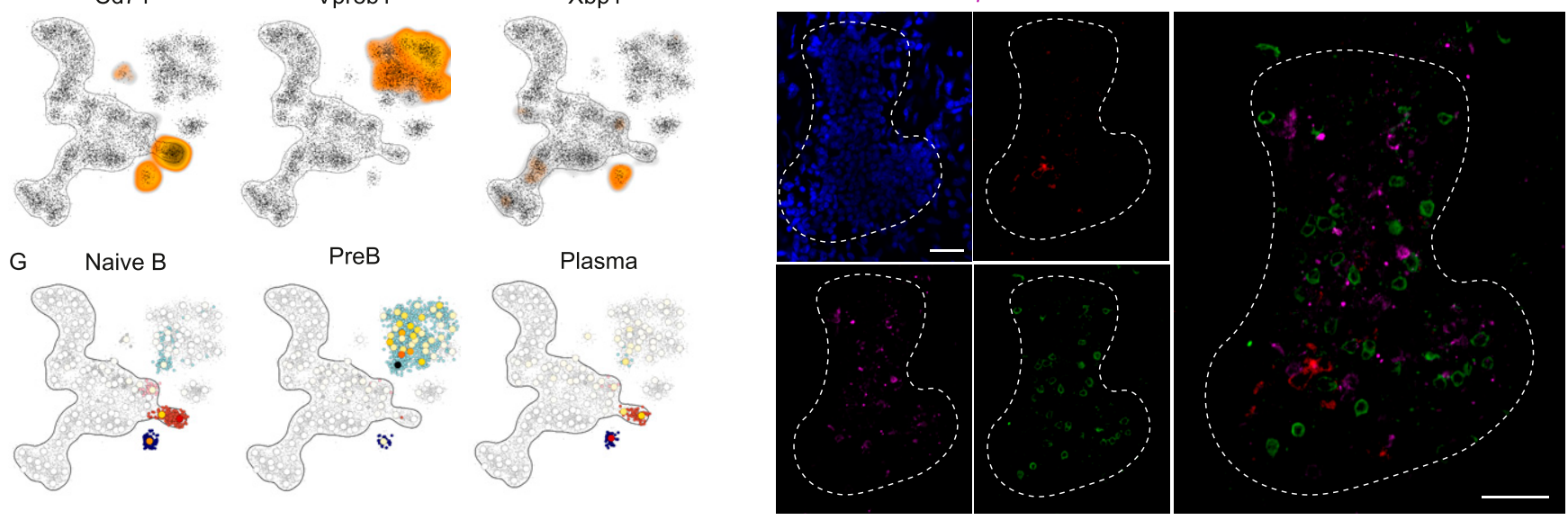

Enrichment in metacell

Figure 6. Unique lymphocyte niche develops at the meninges of SOD1 mice but not at the peripheral CLN.

(A) TCR $\beta^{+}$T cells and B220 $\mathrm{B}$ cells were single cell sorted from spinal cord meninges and cLN of SOD1 mice at different ages (92, 106, 136, and 161 d). Gene expression profiles of $\mathrm{CD}^{+} \mathrm{T}$ cells and B220 $\mathrm{B}$ cells were annotated based on specific cellular subtypes. (B) Cell type distribution of CD4 ${ }^{+} \mathrm{T}$ and B220 ${ }^{+}$B cells in the spinal cord meninges (right bars) and CLN (left bars), at relatively early (92 and $106 \mathrm{~d}$ old) and late (136 and $161 \mathrm{~d}$ old) stages of disease progression. Color scale is according to cell annotation in (A). (C, D) Differential gene expression between naïve B cells and pre-B cells (C), and between naïve B cells and plasma B cells (D). (E, F) A two-dimensional representation of the metacell analysis of $C D 45^{+}$immune cells isolated from adult mouse bone marrow (E). MetaCells related to $B$ cell lineages were annotated according 
high expression of $\mathrm{Ccl5}^{\mathrm{hi}}, \mathrm{Xcl1}$, and Il2rb), S100a4 ${ }^{+} \mathrm{T}$ cells (S100a4, S100a6, and Lgals1), CD8 ${ }^{+} T$ cells (Cd8a and Cd8b1), and naïve T cells (Tcrb and Tcf7). In the B-cell compartment, we identified four main cell subsets, including naïve B cells (Cd79b, Cd74, and H2-Aa), plasma B cells (Xbp1, Mzb1, Iglj1, and Ssr4), pre-plasma B cells, which express the $\mathrm{Fcmr}$ gene, and also exhibited a partial shared gene expression profile with plasma B cells (Iglj1 and Cxcr4), and pre-B cells, which were characterized by low expression levels of genes involved in antigen presentation ( $\mathrm{Cd} 74$ and $\mathrm{H} 2-\mathrm{Aa}$ ), but high expression of Vpreb3 and Dnajc7 (Fig 6A). Interestingly, we also found a cycling subset of pre-B cells with high expression of proliferative genes such as Mki67, Top2a and Ube2c (Fig 6A). For dynamic analysis of cell types across different time points of disease progression, we determined metacell composition in CLN compared with meninges in mSOD1 mice at early (pool of days 92 and 106) and late (pool of days 136 and 161) stages of the disease. While at the early stages of the disease, we found an enrichment of $T$ cells relative to $B$ cells, during the late phase of disease progression, the opposite trend appeared, and B cells accumulated in the meninges (Fig 6B). Such B-cell accumulation and dynamic lymphocyte composition was absent in the CLN (Fig 6B). A thorough cell-state analysis showed that metacell composition varied widely between tissues and across disease stages. Similar to our observations following $\mathrm{SCl}$, the most prominent cellular dynamics along disease progression in SOD1 mice were observed in the meninges, rather than in the CNS-draining CLN (Fig 6B). Whereas naive and $C D 8^{+} T$ cells were enriched in the $C L N$, we found massive accumulation of unique $\mathrm{Ccl}^{+}$and $\mathrm{S} 100 \mathrm{a} 4^{+} \mathrm{T}$-cell populations in the meninges, mainly during the early stages of disease. In the B-cell compartment, the population of pre-B cells was evident in the meninges, from early stages of disease progression onward, whereas this populaton was absent in the $\mathrm{CLN}$ at all tested time points along disease progression. Interestingly, whereas the pre-plasma state was present in both $C L N$ and the meningeal compartments along all stages of disease progression, the plasma B-cell state appeared only in the meningeal compartment, and only during the late stage of the disease (Fig 6B).

Comparison of differential gene expression between naive and activated states of the lymphocytes in the meninges showed that the meningeal lymphocyte niche is unique, enabling a specific $B$ cell trajectory, with activation of developmental and mitochondrial genes by pre-B cells (Vpreb3, Sox4, CD24a, Dnajc7, Tifa and Ucp2; Fig $6 C)$, and unique plasma cell and isotype switching gene programs (Xbp1, Mzb1, Jchain, Ighg3, Ighm, Igkc; Fig 6D). Differential gene expression analysis between the unique meningeal T-cell populations and the naive T-cell state emphasized the distinct gene signature of the meningeal T-cell populations, including $\mathrm{CCl}^{+}$cells, which highly expressed the activation markers Xcl1, Nr4a2, and Il2rb (Fig S2C) and S100a $4^{+}$cells, characterized by the expression of Lgals1, S100a4, S100a6, and Gzma (Fig S2D).
The exclusive B cell niche induced in the spinal cord meninges along disease progression of ALS, in the form of pre-B cells, and the appearance of plasma $B$ cells specifically during late stages of the disease, prompted us to thoroughly investigate and validate these meningeal novel B-cell states. To this end, we used published single-cell RNA-seq data of the mouse bone marrow hematopoietic niche (Giladi et al, 2018), and specifically, focused on the B-cell compartment (Fig 6E). By using the clustering of leukocytes isolated from mouse bone marrow along the hematopoietic process, we annotated pre-B cells (highly expressing the Vpreb1 and Vpreb3 genes), cDCs (expressing Cd74), pDCs (highly expressing Siglech), and plasma cells (highly expressing Xbp1) (Figs 6F and S2E). Interestingly, mutual nearest neighbor projection of meningeal single-cell RNA-seq data on the clustering and annotation of bone marrow hematopoiesis, revealed the stronest overlap between the pre-B and plasma cell states of $B$ cells identified in the spine meninges during ALS progression, and in the bone marrow hematopoietic niche (Figs 6 G and S2F and G). Importantly, immunostaining of mSOD1 meninges for $\mathrm{B}, \mathrm{T}$, and DC populations revealed that, as we found in spine meninges after $\mathrm{SCl}$, cells tend to aggregate, and to form dense lymphocyte structures (Fig 6H).

These results emphasize that in a model of chronic spinal cord degeneration, an activated lymphocyte niche is induced within the spinal cord meninges along disease progression, representing an immune response distinct from that present in the peripheral CNSdraining $C L N$. The presence of meningeal lymphocytes with a unique immunological phenotype at early stages of disease progression is intriguing, but additional studies are required to determine their role, if any, in ALS etiology.

\section{Discussion}

In the present study, we identified a unique lymphoid cell niche within the spinal cord meninges formed under several spinal cord pathologies, including $\mathrm{SCl}$, inflammatory autoimmune disease (EAE), and chronic neurodegeneration (ALS).

A closer look into the meningeal composition under acute and chronic pathologies of the spinal cord revealed the formation of active meningeal lymphocyte niches with lymph node-like properties, including the presence of chemokines, blood and lymph vessels, lymphocyte segregation, and plasma cells. We view these structures as reminiscent of TLS within the meninges.

We found these meningeal TLS-like ectopic structures during the late phase of response to acute injury, when apparently moderate levels of unresolved inflammation persist within the spinal cord parenchyma (Shechter et al, 2009; Cohen et al, 2014, 2017; Raposo et al, 2014). These meningeal structures were observed in close proximity to the site of insult within the parenchyma, harboring cells with immunological properties that differed from the lymphocytes found in the spinal cord parenchyma or in the $C L N$. The

to hallmark gene expression (F). (G) Mutual nearest neighbor projection of meningeal naïve B, pre-B, and plasma B cells on the two-dimensional representation of the metacell analysis of $\mathrm{CD}_{4} 5^{+}$immune cells isolated from adult mouse bone marrow. $\mathbf{( H )}$ Representative immunofluorescent whole-mount staining of meninges derived from $145 \mathrm{~d}$ old SOD1 mouse. Scale bar; $30 \mu \mathrm{m}$. $\mathrm{N}_{\text {total }}=16$ mice; $\mathrm{n}=4-12$ mice for each time point. 
meningeal structures shared features reminiscent of TLS found in chronic inflammatory pathologies, including the synovium in rheumatoid arthritis, and salivary glands in Sjögren syndrome (Schroder et al, 1996; Moyron-Quiroz et al, 2004; Dieu-Nosjean et al, 2014; Pitzalis et al, 2014).

The occurrence of ectopic GC within the CNS has been mainly documented under pathological inflammatory conditions, such as those occurring in the autoimmune disease, multiple sclerosis (Magliozzi et al, 2004, 2007; Serafini et al, 2004; Peters et al, 2011). Moreover, the formation of organized lymphoid aggregates by CNSinfiltrating cells in the subarachnoid space of the spinal cord was observed after transfer of MOG-specific Th17 cells (a model of EAE) (Peters et al, 2011). Here, we found that the meningeal compartment maintains a lymphogenesis infrastructure signaling during homeostasis, and a "sterile" mechanical injury can also induce the formation of TLS in the spinal cord meninges. The meningeal lymphocyte clusters manifested several hallmarks of LN (Aloisi \& Pujol-Borrell, 2006), including expression of chemokines associated with neo-lymphogenesis (Luther et al, 2000; Shi et al, 2001; Xu et al, 2003). Notably, TLS are known as ectopic lymphoid structures and represent accumulations of lymphocytes and stromal cells in an organized structure occurring outside of the SLO (Shipman et al, 2017); moreover, lymphatic vessels are pivotal players in the development of TLS and can enable drainage to the SLO.

Within the CNS, meningeal lymphatics were thoroughly studied in recent years in the dura sinuses of the brain in homeostasis (Weller et al, 2009; Aspelund et al, 2015; Louveau et al, 2015; Absinta et al, 2017), and during neuroinflammation, aging and Alzheimer's disease (Da Mesquita et al, 2018). Using in vivo magnetic resonance imaging techniques, meningeal lymphatic vessels were also identified in both humans, and in nonhuman primates (Absinta et al, 2017). Meningeal lymphatic vessels were shown to play a critical role in the trafficking of immune cells in the brain, in particular enabling T- and B-cell egress into draining lymph nodes (Louveau et al, 2015). In addition, the lymphatics might be connected to the "glymphatic" system, associated with waste management and clearance of interstitial solutes (Aspelund et al, 2015), and may also promote clearance of brain edema. Here, we suggest these meningeal lymphatic vessels can also provide the necessary support for the formation of TLS. Of note, the distance between the lesion site and peripheral SLO, might explain the need for a local ectopic lymphoid niche. Further studies regarding the origin of the meningeal lymphocytes should be performed, by examining whether they are recruited to the meninges from the periphery or from the lesion site in the spinal cord parenchyma.

The formation of a unique lymphocyte niche within the spinal cord meninges in chronic neurodegenerative conditions, as observed here along disease progression in the ALS mouse model, even before full manifestation of functional loss, and before the appearance of immune signaling in peripheral lymphatic sites, supports the existence of a regulated immune response within the CNS territory as a local immunological event that might precede the systemic immune response. This response, induced by CNS-specific mechanisms, is apparently different from those occurring in other tissues, suggesting that the meningeal response is an "ad hoc" transition station, serving as an interim communication node between the CNS and the circulation. Further studies are needed to fully elucidate the role and the effect of these niches on the fate of the parenchyma.

\section{Materials and Methods}

\section{Animals}

Mouse strains used is the study: $\mathrm{C} 57 \mathrm{BL} / 6 \mathrm{~J}$ were obtained from Harlan Biotech; CD11C ${ }^{\text {DTR }}$ (B6.FVB-Tg Itgax-DTR/GFP 57Lan/J), carrying a transgene encoding a human diphtheria toxin receptor (DTR) under control of the murine CD11c promoter (Jung et al, 2002) were a generous gift from Prof Steffen Jung; and mSOD1 mice were obtained from animal breeding center at Ben-Gurion University of the Negev. Adult male mice aged 8-10 wk were used, unless indicated differently, as in the mSOD1 model. All animals were handled according to the regulations formulated by the Institutional Animal Care and Use Committee (IACUC).

\section{Scanning electron microscopy}

Animals were perfused with fixative (3\% PFA [Merck], 2\% glutaraldehyde [EMS] in $0.1 \mathrm{M}$ cacodylate buffer, $5 \mathrm{nM} \mathrm{CaCl}_{2}$, and $1 \%$ sucrose) and the meninges adjacent to the lesion site carefully dissected. After overnight post-fixation in 3\% PFA and 2\% glutaraldehyde, samples were fixed with $1 \%$ osmium tetroxide (EMS) in $0.1 \mathrm{M}$ cacodylate buffer, $5 \mathrm{nM} \mathrm{CaCl}$, and $1 \%$ sucrose for $1.5 \mathrm{~h}$. They were then incubated with 1\% tannic acid (Merck) in DDW for 5 min, followed by incubation with $1 \%$ uranyl acetate (EMS) in DDW for 30 min. Samples were dehydrated by washing with ethanol at increasing concentrations, and then dried in a critical point dryer (Bal-Tec 030; Leica). After the samples were mounted onto aluminum stubs, they were sputter-coated with gold-palladium and imaged with a Zeiss Ultra 55 FEG SEM.

\section{Spinal cord injury}

The spinal cords of deeply anesthetized mice were exposed by laminectomy at T12, and a contusive (200 kdynes) centralized injury was performed, using the Infinite Horizon spinal cord impactor (Precision Systems), as previously described (Shechter et al, 2009). The animals were maintained on twice-daily bladder expression. Animals that were contused in a non-symmetrical manner (point difference of $>2$ between their two hind limbs) were excluded from the experimental analysis.

\section{Active immunization}

In the EAE induction, mice were immunized with $\mathrm{MOG}_{35-55}$ peptide and euthanized $14 \mathrm{~d}$ later. To this end, $200 \mu \mathrm{g}$ of MOG $35-55$ peptide (GL Biochem Ltd.) was emulsified in incomplete Freund's adjuvant containing $0.5 \mathrm{mg} / \mathrm{ml}$ Mycobacterium tuberculosis (strain H37Ra; BD Diagnostics), and $200 \mu \mathrm{l}$ of the mixture was injected subcutaneously to the mice. Pertussis toxin was not administered as part of the EAE induction. 


\section{BrdU administration}

5-Bromo-2-deoxyuridine (BrdU; Sigma-Aldrich) was dissolved by sonication in phosphate-buffered saline and injected intra-peritoneally (75 $\mathrm{mg} \mathrm{kg}^{-1}$ body weight) on day 13 , and on the next day, $1 \mathrm{~h}$ before euthanizing the animals.

\section{Isolation of meningeal layers}

Mice subjected to $\mathrm{SCl}$ were killed by an overdose of anesthetic followed by perfusion with PBS via the left cardiac ventricle. Spinal cord sections were cut from individual mice, including the injury site and adjacent margins ( $1 \mathrm{~cm}$ long). Spinal cord and brain meninges and parenchyma were separated by careful meningeal dissection under a binocular microscope. For the experiments involving separation of each of the three layers, identification of dura, arachnoid, and pia mater was based on their anatomical location relative to the spinal cord parenchyma and vertebra, and architecture; the dura mater was defined as the outermost thick membrane, located closest to the bones of the vertebra; the innermost pia membrane was a fibrous thin delicate membrane attached to the glial limitans enclosing the spinal cord parenchyma; and the middle arachnoid membrane was a thin, transparent membrane with a webbed sack-like appearance. Photomicrographs of spine meninges during microdissection were taken using a Universal Professional Photography HD 18× Macro Lens (Apexel) and iPhone XR (Apple).

For whole-mount staining of the meningeal tissue, the dissected meninges were immediately fixed in 4\% PFA for $24 \mathrm{~h}$, and then transferred to PBS containing $0.05 \%$ sodium azide.

For flow cytometry analysis and sorting of the meningeal cells for qRT-PCR analysis, the dissected tissues were digested for $45 \mathrm{~min}$ with $400 \mathrm{U} / \mathrm{ml}$ Collagenase type IV, at $37^{\circ} \mathrm{C}$, followed by vigorous homogenization of the tissue in the staining buffer. For flow cytometry analysis and sorting of the spinal cord parenchyma, the tissue was homogenized using a software controlled sealed homogenization system (Dispomix, Medic Tools; Miltenyi), followed by resuspension in $40 \%$ Percoll for leukocyte separation.

For flow cytometry analysis and sorting of cLN lymphocytes, tissues were mechanically homogenized, and cells were washed with ice-cold sorting buffer (PBS supplemented with $0.2 \mathrm{mM}$ EDTA, $\mathrm{pH} 8$, and 0.5\% BSA).

For single-cell sorting and analysis, CLN were digested in IMDM (Sigma-Aldrich) media supplemented with Liberase-TL $(100 \mu \mathrm{g} / \mathrm{ml}$; Roche) and DNase-I (100 $\mu \mathrm{g} / \mathrm{ml}$; Roche), and spinal cord meninges were digested in Roswell Park Memorial Institute (Sigma-Aldrich) media supplemented with collagenase IV (40 U/ml; Roche) and DNase-I (100 $\mu \mathrm{g} / \mathrm{ml}$; Roche). Both tissues were incubated with frequent agitation at $37^{\circ} \mathrm{C}$ for $20 \mathrm{~min}$. After the dissociation procedures, the cells were washed with sorting buffer, filtered through 100-, 70-, and 40- $\mu \mathrm{m}$ cell strainers, and centrifuged at $380 \mathrm{~g}$, for $5 \mathrm{~min}$, at $4^{\circ} \mathrm{C}$.

\section{Immunohistochemistry}

Paraffin-embedded sections were used for the staining of tissue sections, which included the spinal cord parenchyma and adjacent meninges. Fixed meningeal layers were used for the whole-mount staining. Before staining, the dissected tissues were washed and blocked (20\% horse serum, $0.3 \%$ Triton X-100, and PBS) for $1 \mathrm{~h}$ at room temperature, with shaking. Whole-mount staining with primary (in PBS containing $2 \%$ horse serum and $0.3 \%$ Triton $\mathrm{X}-100$ ) or secondary antibodies (in PBS) was performed for $1 \mathrm{~h}$ at room temperature, with shaking. Each step was followed by three washes in PBS. The tissues were applied to slides, mounted with Immumount (Thermo Fisher Scientific Shandom), and sealed with coverslips. The following antibodies were used: rabbit anti-GFP (1:100; $M B L)$, hamster anti-TCR $\beta$ (1:50; BioLegend), rat anti-CD3 (1:200; Serotec), rat anti-B220 (1:50; Abcam), rat anti-Ki67 (1:50; Abcam), rat anti-BrdU (1:100; Abcam), rat anti-CD31 (PECAM-1; 1:100; BD Bioscience), rat anti-pan-endothelial cell antigen (MECA-32; 1:10), rat antireticular fibroblast (ER-TR7; 1:100; Abcam), anti-LYVE-1 (1:100; Abcam), goat anti-CCL21 (1:50; R\&D Systems), goat anti-CXCL13 (1:50; R\&D systems), anti-IgD (1:100; Abcam), anti-IgM (1:100; Abcam), biotin antiB220 (1:100; BioLegend), and armenian hamster anti-CD11C (1:100; BioLegend). The slides were exposed to Hoechst stain $(1: 4,000$; Invitrogen Probes) for 1 min. For microscopic analysis, a Nikon light microscope (Eclipse E800) equipped with a Nikon digital camera (DSRi1), or fluorescence microscope (Eclipse 80i) equipped with a Nikon digital camera (DXM1200F) were used. Longitudinal sections of the spinal cord were analyzed. Evaluation of cell number was performed manually. To avoid overestimation due to counting of partial cells that appeared within the section, special care was taken to count only cells with intact morphology and a nucleus that appeared larger than $4 \mu \mathrm{m}$ in diameter. A cluster was defined as an aggregate of 10 or more cells. Three sections from different depths were assessed for each animal in the paraffin-fixed sections; for whole-mount analysis, 3-4 meningeal samples were used.

\section{Flow cytometry and sorting}

Cells were suspended in ice cold sorting buffer (PBS supplemented with $0.2 \mathrm{mM}$ EDTA pH 8 and $0.5 \%$ BSA) supplemented with antimouse CD16/32 (BD Bioscience) to block Fc receptors before labelling with fluorescent antibodies against cell surface epitopes. Samples were stained using the following antibodies: PE-conjugated B220, Alexa 700-conjugated B220, Pacific Blue-conjugated B220, APCconjugated TCR $\beta$, FITC-conjugated TCR $\beta$, Pacific Blue-conjugated CD4, $\mathrm{PE}$-conjugated $\mathrm{CD} 3$, PE-conjugated CD44, PE-conjugated CD27, purified anti-mouse IgD, PE-conjugated IgM, APC-cy7-conjugated MHC-II, FITCconjugated CD45.2, and FITC-conjugated CD4 were purchased from BioLegend; PerCPcy5.5-conjugated CD3 was purchased from eBiosciences; APC-conjugated CD62L was purchased from BD Bioscience; FITC-conjugated PNA was purchased from Sigma-Aldrich; APC-conjugated CD138 was purchased from R\&D Systems; and Alexa-647-conjugated GL7 was purchased from Abcam.

For single-cell sorting, CLN and meninges-derived lymphocytes were suspended in ice-cold sorting buffer supplemented with anti-mouse CD16/32 (BD Bioscience) to block Fc receptors before labelling with fluorescent antibodies against cell surface epitopes. Samples were stained using the following antibodies: eFluor450-conjugated TER-119 and APC-conjugated CD45 were purchased from eBioscience, PE-conjugated B220 and FITCconjugated TCR $\beta$ were purchased from BioLegend. Cells were 
stained with DAPI for evaluation of live/ dead cells. For sorting of $T$ and $B$ cells, the samples were first gated for exclusion of dead cells (DAPI ${ }^{-}$) and erythrocytes (TER119 ${ }^{-}$). Cell populations were sorted with an ARIA-III instrument (BD Biosciences) and analyzed using BD FACSDIVA software (BD Bioscience) and FlowJo software (FlowJo, LLC).

Isolated live cells were single cell sorted into 384-well cell capture plates containing $2 \mu \mathrm{l}$ of lysis solution and barcoded poly $(\mathrm{T})$ RT primers for single-cell RNA-seq (Jaitin et al, 2014). Four wells were kept empty in each 384-well plate as a no-cell control during data analysis. Immediately after sorting, each plate was spun down to ensure full immersion of cells in the lysis solution, and stored at $-80^{\circ} \mathrm{C}$ until processing.

\section{Quantitative real-time PCR}

RNA was extracted from meningeal samples (adjacent to the lesion site, $1 \mathrm{~cm}$ length) using the RNeasy Fibrous Tissue Mini Kit (QIAGEN). For cell samples sorted by flow cytometry, total RNA was extracted using the miRNeasy mini kit (Quiagen). Random hexamers ( $A B$ ) were used for first-strand CDNA synthesis. The procedures were performed according to the manufacturer's instructions. The relative amounts of mRNA were calculated by using the standard curve method, and were normalized to the housekeeping gene, peptidylprolyl isomerase A (PpiA). Each RNA sample was run in triplicate. Primer sequences are listed in the Supplemental Experimental Procedures section.

\section{MARS-seq library preparation}

Single-cell libraries were prepared as previously described (Jaitin et al, 2014; Keren-Shaul et al, 2019). In brief, mRNA from cells sorted into cell capture plates was barcoded and converted into cDNA and pooled using an automated pipeline. The pooled sample was then linearly amplified by $\mathrm{T} 7$ in vitro transcription, and the resulting RNA was fragmented and converted into a sequencing-ready library by tagging the samples with pool barcodes and Illumina sequences during ligation, RT, and PCR. Each pool of cells was tested for library quality, and concentration was assessed as described earlier.

\section{MARS-seq low-level data processing}

Single-cell RNA-seq libraries (pooled at equimolar concentration) were sequenced on an Illumina NextSeq 500 at a median sequencing depth of 25,274 reads per cell. Sequences were mapped to the mouse genome (mm10), demultiplexed, and filtered as previously described (Jaitin et al, 2014) with the following adaptations. Mapping of reads was performed using HISAT (version 0.1.6); reads with multiple mapping positions were excluded. Reads were associated with genes if they were mapped to an exon, using the UCSC genome browser for reference. We estimated the level of spurious unit molecular identifiers (UMIS) in the data using statistics generated from empty MARS-seq wells. Cells with less than $500 \mathrm{UMI}$, more than 500,000 UMI, or with more than $50 \%$ mitochondrial genes were excluded from analysis.
The MetaCell pipeline (Baran et al, 2019) was used to derive informative genes and compute cell-to-cell similarity, to compute K-nn graph covers and derive distribution of RNA in cohesive groups of cells (or metacells), and to derive strongly separated clusters using bootstrap analysis and computation of graph covers on resampled data. Default parameters were used unless otherwise stated. A metacell cover was produced on a combined dataset of cells from all tissues ( $L N$ and meninges) and disease states (early and late). Two-dimensional visualization of the metacell structure was performed as previously described (Baran et al, 2019). In short, a symmetric graph was constructed over all metacells, by thresholding over the co-clustering statistics (indicating how likely cells from two distinct metacells will be clustered together). This resulted in a graph with maximum degree $D$ and any number of connected components. MetaCell computes coordinates for each metacell by applying a standard force-directed layout algorithm to the graph. It then positions cells by averaging the metacell coordinates of their neighbor cells in the K-nn graph, but filters neighbors that define a metacell pair that is not connected in the graph. MetaCell approximates the gene expression intensity within each metacell by a regularized geometric mean. It then quantifies relative expression as the log fold enrichment over the median metacell value. To annotate metacells and assign them into monocyte and macrophage states, a supervised approach was implemented, where metacells are assigned (or colored) into functional groups by expression of a curated list of marker genes. Each marker was assigned a threshold value, and all metacells whose lfp value for that marker were above the threshold were colored for that marker. In case of a conflict, a priority parameter was used to decide which marker is dominant over assignment by other markers.

Bone marrow scRNA-seq data were obtained from our previous publication (Giladi et al, 2018), describing a metacell model of 12,051 cKit $^{+}$lineage ${ }^{-}$bone marrow hematopoietic stem and progenitor cells. To project meningeal B subsets on the bone marrow ScRNAseq dataset, mutual $\mathrm{K}$ nearest neighbors analysis was performed, with $K=100$. Neighbors were determined based on Pearson correlation over the log-transformed size-normalized UMI tables of the marker genes used to derive bone marrow clustering model. Fig $6 \mathrm{G}$ depicts, for each meningeal subset, all its mutual nearest neighbors in the bone marrow dataset.

\section{Statistical analysis}

Data were analyzed using the $t$ test to compare between two groups. One-way ANOVA was used to compare several groups; the Tukey's honestly significant difference procedure was used for follow-up pairwise comparison of groups. The specific tests used to analyze each experiment are indicated in the figure legends. The results are presented as mean \pm SEM.

\section{Data Availability}

The accession number for the raw and processed scRNA-seq data reported in this article is Gene Expression Omnibus: GSE160193 Software and custom code will be available by request. 


\section{Supplementary Information}

Supplementary Information is available at https://doi.org/10.26508/lsa. 202000907.

\section{Acknowledgements}

Research in the M Schwartz lab is supported by Advanced European Research Council grants (232835), and by the European Seventh Framework Program HEALTH-2011 (279017); Israel Science Foundation (ISF)-research grant no. 991/16; and ISF-Legacy Heritage Bio-medical Science Partnershipresearch grant no. 1354/15. The research of I Amit is supported by the Seed Networks for the Human Cell Atlas of the Chan Zuckerberg Initiative and by Merck KGaA, Darmstadt. I Amit is an incumbent of the Eden and Steven Romick Professorial Chair, supported by the Howard Hughes Medical Institute International Scholar Award, the European Research Council Consolidator Grant (no. 724471-HemTree2.0), an melanoma research alliance Established Investigator Award (no. 509044), Deutsche Forschungsgemeinschaft (DFG) (no. SFB/ TRR167), the Ernest and Bonnie Beutler Research Program for Excellence in Genomic Medicine, the Helen and Martin Kimmel awards for innovative investigation, and the award of the Wolfson Foundation and Family Charitable Trust. The Thompson Family Foundation Alzheimer's Research Fund and the Adelis Foundation also provided support. RG Lichtenstein is supported by Keren Hayesod, Magbit France.

\section{Author Contributions}

M Cohen: conceptualization, data curation, formal analysis, supervision, validation, investigation, visualization, methodology, project administration, and writing-original draft, review, and editing. A Giladi: data curation, software, validation, and investigation. C Raposo: conceptualization, formal analysis, validation, investigation, methodology, and writing-original draft, review, and editing. M Zada: investigation.

B Li: investigation.

J Ruckh: investigation.

A Deczkowska: investigation.

B Mohar: investigation.

R Shechter: conceptualization.

RG Lichtenstein: conceptualization, resources, supervision, and investigation.

I Amit: conceptualization, resources, supervision, and investigation. M Schwartz: conceptualization, resources, data curation, formal analysis, supervision, funding acquisition, validation, investigation, visualization, methodology, project administration, and writingoriginal draft, review, and editing.

\section{Conflict of Interest Statement}

The authors declare that they have no conflict of interest.

\section{References}

Absinta M, Ha SK, Nair G, Sati P, Luciano NJ, Palisoc M, Louveau A, Zaghloul KA, Pittaluga S, Kipnis J, et al (2017) Human and nonhuman primate meninges harbor lymphatic vessels that can be visualized noninvasively by MRI. Elife 6: e29738. doi:10.7554/elife.29738
Aloisi F, Pujol-Borrell R (2006) Lymphoid neogenesis in chronic inflammatory diseases. Nat Rev Immunol 6: 205-217. doi:10.1038/nri1786

Amft N, Curnow SJ, Scheel-Toellner D, Devadas A, Oates J, Crocker J, Hamburger J, Ainsworth J, Mathews J, Salmon M, et al (2001) Ectopic expression of the B cell-attracting chemokine BCA-1 (CXCL13) on endothelial cells and within lymphoid follicles contributes to the establishment of germinal center-like structures in Sjogren's syndrome. Arthritis Rheum 44: 2633-2641. doi:10.1002/15290131(200111)44:11<2633::aid-art443>3.0.co;2-9

Aspelund A, Antila S, Proulx ST, Karlsen TV, Karaman S, Detmar M, Wiig H, Alitalo K (2015) A dural lymphatic vascular system that drains brain interstitial fluid and macromolecules. J Exp Med 212: 991-999. doi:10.1084/jem.20142290

Baluk P, McDonald DM (2008) Markers for microscopic imaging of lymphangiogenesis and angiogenesis. Ann N Y Acad Sci 1131: 1-12. doi:10.1196/annals.1413.001

Baran Y, Bercovich A, Sebe-Pedros A, Lubling Y, Giladi A, Chomsky E, Meir Z, Hoichman M, Lifshitz A, Tanay A (2019) MetaCell: Analysis of single-cell RNA-seq data using K-nn graph partitions. Genome Biol 20: 206. doi:10.1186/s13059-019-1812-2

Barr TA, Shen P, Brown S, Lampropoulou V, Roch T, Lawrie S, Fan B, O'Connor RA, Anderton SM, Bar-Or A, et al (2012) B cell depletion therapy ameliorates autoimmune disease through ablation of IL-6-producing B cells. J Exp Med 209: 1001-1010. doi:10.1084/jem.20111675

Bevan RJ, Evans R, Griffiths L, Watkins LM, Rees MI, Magliozzi R, Allen I, McDonnell G, Kee R, Naughton M, et al (2018) Meningeal inflammation and cortical demyelination in acute multiple sclerosis. Ann Neurol 84: 829-842. doi:10.1002/ana.25365

Brustle A, Heink S, Huber M, Rosenplanter C, Stadelmann C, Yu P, Arpaia E, Mak TW, Kamradt T, Lohoff M (2007) The development of inflammatory $\mathrm{T}(\mathrm{H})-17$ cells requires interferon-regulatory factor 4. Nat Immunol 8: 958-966. doi:10.1038/ni1500

Carare RO, Hawkes CA, Weller RO (2014) Afferent and efferent immunological pathways of the brain. Anatomy, function and failure. Brain Behav Immun 36: 9-14. doi:10.1016/j.bbi.2013.10.012

Cohen M, Ben-Yehuda H, Porat Z, Raposo C, Gordon S, Schwartz M (2017) Newly formed endothelial cells regulate myeloid cell activity following spinal cord injury via expression of CD200 ligand. I Neurosci 37: 972-985. doi:10.1523/jneurosci.2199-16.2017

Cohen M, Matcovitch O, David E, Barnett-Itzhaki Z, Keren-Shaul H, BlecherGonen R, Jaitin DA, Sica A, Amit I, Schwartz M (2014) Chronic exposure to TGFbeta1 regulates myeloid cell inflammatory response in an IRF7dependent manner. EMBO / 33: 2906-2921. doi:10.15252/embj.201489293

Columba-Cabezas S, Griguoli M, Rosicarelli B, Magliozzi R, Ria F, Serafini B, Aloisi $F$ (2006) Suppression of established experimental autoimmune encephalomyelitis and formation of meningeal lymphoid follicles by lymphotoxin beta receptor-Ig fusion protein. J Neuroimmunol 179: 76-86. doi:10.1016/j.jneuroim.2006.06.015

Da Mesquita S, Louveau A, Vaccari A, Smirnov I, Cornelison RC, Kingsmore KM, Contarino C, Onengut-Gumuscu S, Farber E, Raper D, et al (2018) Functional aspects of meningeal lymphatics in ageing and Alzheimer's disease. Nature 560: 185-191. doi:10.1038/s41586-0180368-8

Dalakas MC (2008) B cells as therapeutic targets in autoimmune neurological disorders. Nat Clin Pract Neurol 4: 557-567. doi:10.1038/ncpneuro0901

David S, Kroner A (2011) Repertoire of microglial and macrophage responses after spinal cord injury. Nat Rev Neurosci 12: 388-399. doi:10.1038/ nrn3053

de Chaisemartin L, Goc J, Damotte D, Validire P, Magdeleinat P, Alifano M, Cremer I, Fridman WH, Sautes-Fridman C, Dieu-Nosjean MC (2011) Characterization of chemokines and adhesion molecules associated with $T$ cell presence in tertiary lymphoid structures in human lung cancer. Cancer Res 71: 6391-6399. doi:10.1158/0008-5472.can-11-0952 
Dieu-Nosjean MC, Goc J, Giraldo NA, Sautes-Fridman C, Fridman WH (2014) Tertiary lymphoid structures in cancer and beyond. Trends Immunol 35: 571-580. doi:10.1016/j.it.2014.09.006

Duddy M, Niino M, Adatia F, Hebert S, Freedman M, Atkins H, Kim HJ, Bar-Or A (2007) Distinct effector cytokine profiles of memory and naive human B cell subsets and implication in multiple sclerosis. J Immunol 178: 6092-6099. doi:10.4049/jimmunol.178.10.6092

Fan L, Reilly CR, Luo Y, Dorf ME, Lo D (2000) Cutting edge: Ectopic expression of the chemokine TCA4/SLC is sufficient to trigger lymphoid neogenesis. J Immunol 164: 3955-3959. doi:10.4049/jimmunol.164.8.3955

Fujii Y, Kawamura H, Kawamura T, Kanda Y, Matsumoto H, Kobayashi T, Yamamoto T, Aoyama T, Abo T (2010) Co-appearance of autoantibodyproducing B220(low) B cells with NKT cells in the course of hepatic injury. Cell Immunol 260: 105-112. doi:10.1016/j.cellimm.2009.09.009

GeurtsvanKessel CH, Willart MA, Bergen IM, van Rijt LS, Muskens F, Elewaut D, Osterhaus AD, Hendriks R, Rimmelzwaan GF, Lambrecht BN (2009) Dendritic cells are crucial for maintenance of tertiary lymphoid structures in the lung of influenza virus-infected mice. J Exp Med 206: 2339-2349. doi:10.1084/jem.20090410

Giladi A, Paul F, Herzog Y, Lubling Y, Weiner A, Yofe I, Jaitin D, CabezasWallscheid N, Dress R, Ginhoux F, et al (2018) Single-cell characterization of haematopoietic progenitors and their trajectories in homeostasis and perturbed haematopoiesis. Nat Cell Biol 20: 836-846. doi:10.1038/s41556-018-0121-4

Gommerman JL, Browning JL (2003) Lymphotoxin/light, lymphoid microenvironments and autoimmune disease. Nat Rev Immunol 3: 642-655. doi:10.1038/nri1151

Grabner R, Lotzer K, Dopping S, Hildner M, Radke D, Beer M, Spanbroek R, Lippert B, Reardon CA, Getz GS, et al (2009) Lymphotoxin beta receptor signaling promotes tertiary lymphoid organogenesis in the aorta adventitia of aged ApoE-/- mice. J Exp Med 206: 233-248. doi:10.1084/jem.20080752

Harris DP, Goodrich S, Gerth AJ, Peng SL, Lund FE (2005) Regulation of IFNgamma production by B effector 1 cells: Essential roles for T-bet and the IFN-gamma receptor. J Immunol 174: 6781-6790. doi:10.4049/ jimmunol.174.11.6781

Harris RJ, Pettitt AR, Schmutz C, Sherrington PD, Zuzel M, Cawley JC, Griffiths SD (2000) Granulocyte-macrophage colony-stimulating factor as an autocrine survival factor for mature normal and malignant B lymphocytes. J Immunol 164: 3887-3893. doi:10.4049/ jimmunol.164.7.3887

Howell OW, Reeves CA, Nicholas R, Carassiti D, Radotra B, Gentleman SM, Serafini B, Aloisi F, Roncaroli F, Magliozzi R, et al (2011) Meningeal inflammation is widespread and linked to cortical pathology in multiple sclerosis. Brain 134: 2755-2771. doi:10.1093/brain/awr182

Jaitin DA, Kenigsberg E, Keren-Shaul H, Elefant N, Paul F, Zaretsky I, Mildner A, Cohen N, Jung S, Tanay A, et al (2014) Massively parallel single-cell RNA-seq for marker-free decomposition of tissues into cell types. Science 343: 776-779. doi:10.1126/science.1247651

Jung S, Unutmaz D, Wong P, Sano G, De los Santos K, Sparwasser T, Wu S, Vuthoori S, Ko K, Zavala F, et al (2002) In vivo depletion of CD11C(+) dendritic cells abrogates priming of CD8(+) T cells by exogenous cellassociated antigens. Immunity 17: 211-220. doi:10.1016/s1074-7613(02) 00365-5

Kawabe S, Abe T, Kawamura H, Gejyo F, Abo T (2004) Generation of B220low B cells and production of autoantibodies in mice with experimental amyloidosis: Association of primordial T cells with this phenomenon. Clin Exp Immunol 135: 200-208. doi:10.1111/j.1365-2249.2003.02361.x

Kendall PL, Yu G, Woodward EJ, Thomas JW (2007) Tertiary lymphoid structures in the pancreas promote selection of B lymphocytes in autoimmune diabetes. J Immunol 178: 5643-5651. doi:10.4049/ jimmunol.178.9.5643

Keren-Shaul H, Kenigsberg E, Jaitin DA, David E, Paul F, Tanay A, Amit I (2019) MARS-seq2.0: An experimental and analytical pipeline for indexed sorting combined with single-cell RNA sequencing. Nat Protoc 14 1841-1862. doi:10.1038/s41596-019-0164-4

Korn T, Mitsdoerffer M, Croxford AL, Awasthi A, Dardalhon VA, Galileos G, Vollmar P, Stritesky GL, Kaplan MH, Waisman A, et al (2008) IL-6 controls Th17 immunity in vivo by inhibiting the conversion of conventional T cells into Foxp3+ regulatory T cells. Proc Natl Acad Sci U S A 105: 18460-18465. doi:10.1073/pnas.0809850105

Kratz A, Campos-Neto A, Hanson MS, Ruddle NH (1996) Chronic inflammation caused by lymphotoxin is lymphoid neogenesis. J Exp Med 183: 1461-1472. doi:10.1084/jem.183.4.1461

Kuerten S, Schickel A, Kerkloh C, Recks MS, Addicks K, Ruddle NH, Lehmann PV (2012) Tertiary lymphoid organ development coincides with determinant spreading of the myelin-specific T cell response. Acta Neuropathol 124: 861-873. doi:10.1007/s00401-012-1023-3

Kunis G, Baruch K, Miller O, Schwartz M (2015) Immunization with a myelinderived antigen activates the brain's choroid plexus for recruitment of immunoregulatory cells to the CNS and attenuates disease progression in a mouse model of ALS. J Neurosci 35: 6381-6393. doi:10.1523/jneurosci.3644-14.2015

Kunis G, Baruch K, Rosenzweig N, Kertser A, Miller O, Berkutzki T, Schwartz M (2013) IFN-gamma-dependent activation of the brain's choroid plexus for CNS immune surveillance and repair. Brain 136: 3427-3440. doi:10.1093/brain/awt259

Lalancette-Hebert M, Gowing G, Simard A, Weng YC, Kriz J (2007) Selective ablation of proliferating microglial cells exacerbates ischemic injury in the brain. J Neurosci 27: 2596-2605. doi:10.1523/jneurosci.536006.2007

Lehmann-Horn K, Wang SZ, Sagan SA, Zamvil SS, von Budingen HC (2016) B cell repertoire expansion occurs in meningeal ectopic lymphoid tissue. JCI Insight 1: e87234. doi:10.1172/jci.insight.87234

Liesz A, Suri-Payer E, Veltkamp C, Doerr H, Sommer C, Rivest S, Giese T, Veltkamp R (2009) Regulatory T cells are key cerebroprotective immunomodulators in acute experimental stroke. Nat Med 15: 192-199. doi:10.1038/nm.1927

Lochhead JJ, Wolak DJ, Pizzo ME, Thorne RG (2015) Rapid transport within cerebral perivascular spaces underlies widespread tracer distribution in the brain after intranasal administration. J Cereb Blood Flow Metab 35: 371-381. doi:10.1038/jcbfm.2014.215

London A, Benhar I, Mattapallil MJ, Mack M, Caspi RR, Schwartz M (2013) Functional macrophage heterogeneity in a mouse model of autoimmune central nervous system pathology. I Immunol 190: 3570-3578. doi:10.4049/jimmunol.1202076

London A, Itskovich E, Benhar I, Kalchenko V, Mack M, Jung S, Schwartz M (2011) Neuroprotection and progenitor cell renewal in the injured adult murine retina requires healing monocyte-derived macrophages. J Exp Med 208: 23-39. doi:10.1084/jem.20101202

Louveau A, Smirnov I, Keyes TJ, Eccles JD, Rouhani SJ, Peske JD, Derecki NC, Castle D, Mandell JW, Lee KS, et al (2015) Structural and functional features of central nervous system lymphatic vessels. Nature 523: 337-341. doi:10.1038/nature14432

Luther SA, Lopez T, Bai W, Hanahan D, Cyster JG (2000) BLC expression in pancreatic islets causes $B$ cell recruitment and lymphotoxindependent lymphoid neogenesis. Immunity 12: 471-481. doi:10.1016/ s1074-7613(00)80199-5

Magliozzi R, Columba-Cabezas S, Serafini B, Aloisi F (2004) Intracerebral expression of CXCL13 and BAFF is accompanied by formation of lymphoid follicle-like structures in the meninges of mice with relapsing experimental autoimmune encephalomyelitis. J Neuroimmunol 148: 11-23. doi:10.1016/j.jneuroim.2003.10.056

Magliozzi R, Howell O, Vora A, Serafini B, Nicholas R, Puopolo M, Reynolds R, Aloisi F (2007) Meningeal B-cell follicles in secondary progressive multiple sclerosis associate with early onset of disease and severe cortical pathology. Brain 130: 1089-1104. doi:10.1093/brain/awm038 
Magliozzi R, Howell OW, Durrenberger P, Arico E, James R, Cruciani C, Reeves C, Roncaroli F, Nicholas R, Reynolds R (2019) Meningeal inflammation changes the balance of TNF signalling in cortical grey matter in multiple sclerosis. J Neuroinflammation 16: 259. doi:10.1186/s12974-019-1650-x

Martino G, Pluchino S, Bonfanti L, Schwartz M (2011) Brain regeneration in physiology and pathology: The immune signature driving therapeutic plasticity of neural stem cells. Physiol Rev 91: 1281-1304. doi:10.1152/ physrev.00032.2010

Michaud JP, Bellavance MA, Prefontaine P, Rivest S (2013) Real-time in vivo imaging reveals the ability of monocytes to clear vascular amyloid beta. Cell Rep 5: 646-653. doi:10.1016/j.celrep.2013.10.010

Moyron-Quiroz JE, Rangel-Moreno J, Kusser K, Hartson L, Sprague F, Goodrich S, Woodland DL, Lund FE, Randall TD (2004) Role of inducible bronchus associated lymphoid tissue (iBALT) in respiratory immunity. Nat Med 10: 927-934. doi:10.1038/nm1091

Mueller SN, Germain RN (2009) Stromal cell contributions to the homeostasis and functionality of the immune system. Nat Rev Immunol 9: 618-629. doi:10.1038/nri2588

Nutt SL, Hodgkin PD, Tarlinton DM, Corcoran LM (2015) The generation of antibody-secreting plasma cells. Nat Rev Immunol 15: 160-171. doi:10.1038/nri3795

Peruzzotti-Jametti L, Donega M, Giusto E, Mallucci G, Marchetti B, Pluchino S (2014) The role of the immune system in central nervous system plasticity after acute injury. Neuroscience 283: 210-221. doi:10.1016/ j.neuroscience.2014.04.036

Peters A, Pitcher LA, Sullivan JM, Mitsdoerffer M, Acton SE, Franz B, Wucherpfennig K, Turley S, Carroll MC, Sobel RA, et al (2011) Th17 cells induce ectopic lymphoid follicles in central nervous system tissue inflammation. Immunity 35: 986-996. doi:10.1016/j.immuni.2011.10.015

Pikor NB, Prat A, Bar-Or A, Gommerman JL (2015) Meningeal tertiary lymphoid tissues and multiple sclerosis: A gathering place for diverse types of immune cells during CNS autoimmunity. Front Immunol 6: 657. doi:10.3389/fimmu.2015.00657

Pitzalis C, Jones GW, Bombardieri M, Jones SA (2014) Ectopic lymphoid-like structures in infection, cancer and autoimmunity. Nat Rev Immunol 14: 447-462. doi:10.1038/nri3700

Raposo C, Graubardt N, Cohen M, Eitan C, London A, Berkutzki T, Schwartz M (2014) CNS repair requires both effector and regulatory T cells with distinct temporal and spatial profiles. J Neurosci 34: 10141-10155. doi:10.1523/jneurosci.0076-14.2014

Rolls A, Shechter R, London A, Segev Y, Jacob-Hirsch J, Amariglio N, Rechavi G, Schwartz M (2008) Two faces of chondroitin sulfate proteoglycan in spinal cord repair: A role in microglia/macrophage activation. PLOS Med 5: e171. doi:10.1371/journal.pmed.0050171

Russo MV, McGavern DB (2015) Immune surveillance of the CNS following infection and injury. Trends Immunol 36: 637-650. doi:10.1016/j.it.2015.08.002

Schroder AE, Greiner A, Seyfert C, Berek C (1996) Differentiation of B cells in the nonlymphoid tissue of the synovial membrane of patients with rheumatoid arthritis. Proc Natl Acad Sci U S A 93: 221-225. doi:10.1073/ pnas.93.1.221
Serafini B, Rosicarelli B, Magliozzi R, Stigliano E, Aloisi F (2004) Detection of ectopic B-cell follicles with germinal centers in the meninges of patients with secondary progressive multiple sclerosis. Brain Pathol 14: 164-174. doi:10.1111/j.1750-3639.2004.tb00049.x

Shechter R, London A, Varol C, Raposo C, Cusimano M, Yovel G, Rolls A, Mack M, Pluchino S, Martino G, et al (2009) Infiltrating blood-derived macrophages are vital cells playing an anti-inflammatory role in recovery from spinal cord injury in mice. PLoS Med 6: e1000113. doi:10.1371/journal.pmed.1000113

Shechter R, Miller O, Yovel G, Rosenzweig N, London A, Ruckh J, Kim KW, Klein E, Kalchenko V, Bendel P, et al (2013) Recruitment of beneficial M2 macrophages to injured spinal cord is orchestrated by remote brain choroid plexus. Immunity 38: 555-569. doi:10.1016/j.immuni. 2013.02.012

Shi K, Hayashida K, Kaneko M, Hashimoto J, Tomita T, Lipsky PE, Yoshikawa H, Ochi T (2001) Lymphoid chemokine B cell-attracting chemokine-1 (CXCL13) is expressed in germinal center of ectopic lymphoid follicles within the synovium of chronic arthritis patients. I Immunol 166: 650-655. doi:10.4049/jimmunol.166.1.650

Shields JD, Kourtis IC, Tomei AA, Roberts JM, Swartz MA (2010) Induction of lymphoidlike stroma and immune escape by tumors that express the chemokine CCL21. Science 328: 749-752. doi:10.1126/science.1185837

Shipman WD, Dasoveanu DC, Lu TT (2017) Tertiary lymphoid organs in systemic autoimmune diseases: Pathogenic or protective? F1000Res 6: 196. doi:10.12688/f1000research.10595.1

Tachikawa S, Kawamura T, Kawamura H, Kanda Y, Fujii Y, Matsumoto H, Abo T (2008) Appearance of B220low autoantibody-producing B-1 cells at neonatal and older stages in mice. Clin Exp Immunol 153: 448-455. doi:10.1111/j.1365-2249.2008.03709.x

Thaunat O, Kerjaschki D, Nicoletti A (2006) Is defective lymphatic drainage a trigger for lymphoid neogenesis? Trends Immunol 27: 441-445. doi:10.1016/j.it.2006.08.003

von Budingen HC, Palanichamy A, Lehmann-Horn K, Michel BA, Zamvil SS (2015) Update on the autoimmune pathology of multiple sclerosis: B-cells as disease-drivers and therapeutic targets. Eur Neurol 73: 238-246. doi:10.1159/000377675

Weller RO, Djuanda E, Yow HY, Carare RO (2009) Lymphatic drainage of the brain and the pathophysiology of neurological disease. Acta Neuropathol 117: 1-14. doi:10.1007/s00401-008-0457-0

Xu B, Wagner N, Pham LN, Magno V, Shan Z, Butcher EC, Michie SA (2003) Lymphocyte homing to bronchus-associated lymphoid tissue (BALT) is mediated by L-selectin/PNAd, alpha4beta1 integrin/VCAM-1, and LFA-1 adhesion pathways. J Exp Med 197: 1255-1267. doi:10.1084/ jem.20010685

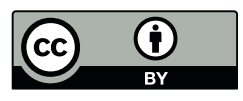

License: This article is available under a Creative Commons License (Attribution 4.0 International, as described at https://creativecommons.org/ licenses/by/4.0/). 